\title{
Chemiluminescent Probe for the in vitro Detection of Protease Activity ${ }^{1}$
}

\author{
Jean-Alexandre Richard ${ }^{\dagger,}$ Ludovic Jean, ${ }^{\ddagger}$ Anthony Romieu, ${ }^{\dagger, *}$ Marc Massonneau, \\ Pauline Noack-Fraissignes, ${ }^{*}$ and Pierre-Yves Renard ${ }^{\dagger, *}$
}

${ }^{\dagger}$ IRCOF, Equipe de Chimie Bio-Organique, UMR 6014 CNRS, INSA et Université de Rouen, 1, rue Lucien Tesnière, 76131 Mont-Saint-Aignan Cedex, France

${ }^{\ddagger}$ QUIDD, Technopôle du Madrillet, 50, rue Ettore Bugatti, 76800 Saint-Etienne du Rouvray, France.

* pierre-yves.renard@univ-rouen.fr or anthony.romieu@univ-rouen.fr.

Phone: +33-2-35-52-24-14 (or 24-15). Fax: +33-2-35-52-29-59.

\section{CONTENT}

1. General methods.

2. Synthesis of the chemilumescent probe $\mathbf{1 2}$.

3. Chemiluminescence in vitro assay.

4. $\quad{ }^{1} \mathrm{H} \mathrm{NMR},{ }^{13} \mathrm{C}$ NMR and ESI mass spectra of compounds 7, 9 and 11. ${ }^{1} \mathrm{H}$ NMR and ESI mass spectra of 11'. ESI mass spectrum of dioxetane 12. RP-HPLC elution profiles of compounds 11, 11' and $\mathbf{1 2}$.

\section{General methods}

Column chromatographies were performed on silica gel (40-63 $\mu \mathrm{m})$ from SdS. TLC were carried out on Merck DC Kieselgel 60 F-254 aluminium sheets. Compounds were visualized by one or both of the following methods: 1) spray with a $0.2 \%(\mathrm{w} / \mathrm{v})$ ninhydrin solution in absolute ethanol, 2) spray with a 3.5\% (w/v) phosphomolybdic acid solution in absolute ethanol. Acetonitrile was freshly distilled over $\mathrm{CaH}_{2}$ under an argon atmosphere prior to use. Dichloromethane was dried by distillation over $\mathrm{P}_{2} \mathrm{O}_{5}$. DIEA and triethylamine were distilled from $\mathrm{CaH}_{2}$ and stored over $\mathrm{BaO}$. Recombinant human caspase-3 and 9 enzymes (respectively $5.52 \mathrm{U} / \mathrm{mg}$ and $7139.39 \mathrm{U} / \mathrm{mg}$ ) were purchased from Sigma. Recombinant A. faecalis PGA $(0.63 \mathrm{U} / \mathrm{mg})$ was gratefully furnished by Pr. L. Fisher, Universität Hohenheim. The HPLC grade acetonitrile $\left(\mathrm{CH}_{3} \mathrm{CN}\right)$ was obtained from Acros or Panreac. Buffers (caspase-3, caspase9, alkaline and phosphate buffers) and aq. mobile phases for HPLC were prepared using deionized water purified with a Milli-Q system (purified to $18.2 \mathrm{M} \Omega . \mathrm{cm}$ ). Triethylammonium bicarbonate (TEAB, $1.0 \mathrm{M}$ ) buffer was prepared from distilled triethylamine and $\mathrm{CO}_{2}$ gas. ${ }^{1} \mathrm{H}$ and ${ }^{13} \mathrm{C}$ NMR spectra were recorded on a Bruker DPX 300 spectrometer (Bruker, Wissembourg, France). Chemical shifts are expressed in parts per million (ppm) from $\mathrm{CDCl}_{3}$ $\left(\delta_{\mathrm{H}}=7.26, \delta_{\mathrm{C}}=77.36\right)$ or $\mathrm{CD}_{3} \mathrm{OD}\left(\delta_{\mathrm{H}}=3.34, \delta_{\mathrm{C}}=49.86\right){ }^{2} J$ values are expressed in Hz. Optical rotations were measured with a Perkin Elmer 341 polarimeter. Infrared (IR) spectra

\footnotetext{
${ }^{1}$ Such chemiluminescent probes were covered by a patent entitled "Preparation of substituted 1,2-dioxetane biomarkers with luminescent emission and their use" filled on May 27, 2005 at the French Patent Office : P.-Y. Renard, A. Romieu, M. Massonneau, FR 2886292 A1 20061201 (WO extension 2006129036).

${ }^{2}$ H. E. Gottlieb, V. Kotlyar, A. Nudelman, J. Org. Chem. 1997, 62, 7512-7515.
} 
were recorded as thin-film on sodium chloride plates or $\mathrm{KBr}$ pellets using a Perkin Elmer FTIR Paragon 500 spectrometer. UV-visible spectra were obtained on a Varian Cary 50 scan spectrophotometer. Fluorescence spectroscopic studies were performed with a Varian Cary Eclipse spectrophotometer. Analytical HPLC was performed on a Thermo Electron Surveyor instrument equipped with a PDA detector. Semi-preparative HPLC was performed on a Finnigan SpectraSYSTEM liquid chromatography system equipped with UV-visible 2000 detector. Mass spectra were obtained with a Finnigan LCQ Advantage MAX (ion trap) apparatus equipped with an electrospray source. Some compounds were characterized by MALDI-TOF mass spectrometry on a Voyager DE PRO in the reflector mode with CHCA as a matrix.

HPLC separations: Several chromatographic systems were used for the analytical experiments and the purification steps:

System A: RP-HPLC (Thermo Hypersil GOLD C 18 column, $5 \mu \mathrm{m}, 4.6$ x $150 \mathrm{~mm}$ ) with $\mathrm{CH}_{3} \mathrm{CN}$ and $0.1 \%$ aq. trifluoroacetic acid (aq. TFA, $0.1 \%, \mathrm{v} / \mathrm{v}, \mathrm{pH} 2.0$ ) as the eluents [80\% TFA (5 $\mathrm{min}$ ), then linear gradient from 20 to $100 \%$ (40 min) of $\mathrm{CH}_{3} \mathrm{CN}$ ] at a flow rate of $1.0 \mathrm{~mL} / \mathrm{min}$. Dual UV-visible detection was achieved at 210 and $254 \mathrm{~nm}$.

System B: RP-HPLC (Thermo Hypersil GOLD C ${ }_{18}$ column, $5 \mu \mathrm{m}, 4.6 \times 150 \mathrm{~mm}$ ) with $\mathrm{CH}_{3} \mathrm{CN}$ and deionized water as the eluents $\left[100 \% \mathrm{H}_{2} \mathrm{O}(5 \mathrm{~min})\right.$, then linear gradient from 0 to $100 \%$ (40 min) of $\mathrm{CH}_{3} \mathrm{CN}$ ] at a flow rate of $1.0 \mathrm{~mL} / \mathrm{min}$. Dual $\mathrm{UV}$-visible detection was achieved at 210 and $254 \mathrm{~nm}$.

System C: RP-HPLC (Thermo Hypersil GOLD C ${ }_{18}$ column, $5 \mu \mathrm{m}, 10$ x $250 \mathrm{~mm}$ ) with $\mathrm{CH}_{3} \mathrm{CN}$ and TFA $0.1 \%$ as the eluents [ $80 \%$ TFA ( $5 \mathrm{~min}$ ), then linear gradients from 20 to $68 \%$ (20 min) of $\mathrm{CH}_{3} \mathrm{CN}, 68 \%$ to $80 \%(10 \mathrm{~min})$ of $\mathrm{CH}_{3} \mathrm{CN}$ and $80 \%$ to $100 \%(5 \mathrm{~min})$ of $\mathrm{CH}_{3} \mathrm{CN}$ ] at a flow rate of $5.0 \mathrm{~mL} / \mathrm{min}$. Dual UV-visible detection was achieved at 210 and $250 \mathrm{~nm}$.

System D: RP-HPLC (Thermo Hypersil GOLD C 18 column, $5 \mu \mathrm{m}, 4.6 \times 150 \mathrm{~mm}$ ) with $\mathrm{CH}_{3} \mathrm{CN}$ and deionized water as the eluents $\left[75 \% \mathrm{H}_{2} \mathrm{O}(2 \mathrm{~min})\right.$, then linear gradient from 25 to $100 \%$ (30 $\min$ ) of $\mathrm{CH}_{3} \mathrm{CN}$ ] at a flow rate of $1.0 \mathrm{~mL} / \mathrm{min}$. Dual $\mathrm{UV}$-visible detection was achieved at 210 and $254 \mathrm{~nm}$.

System E: RP-HPLC (Thermo Hypersil GOLD C 18 column, $5 \mu \mathrm{m}, 10 \times 250 \mathrm{~mm}$ ) with $\mathrm{CH}_{3} \mathrm{CN}$ and deionized water as the eluents $\left[75 \% \mathrm{H}_{2} \mathrm{O}(3 \mathrm{~min})\right.$, then linear gradients from 25 to $65 \%$ (15 min) of $\mathrm{CH}_{3} \mathrm{CN}$ and $65 \%$ to $100 \%(60 \mathrm{~min})$ of $\left.\mathrm{CH}_{3} \mathrm{CN}\right]$ at a flow rate of $5.0 \mathrm{~mL} / \mathrm{min}$. Dual UVvisible detection was achieved at 210 and $250 \mathrm{~nm}$.

System F: RP-HPLC (Thermo Hypersil GOLD C 18 column, $5 \mu \mathrm{m}, 10$ x $250 \mathrm{~mm}$ ) with $\mathrm{CH}_{3} \mathrm{CN}$ and triethylammonium bicarbonate (TEAB $50 \mathrm{mM}, \mathrm{pH} 7.5)$ as the eluents [100\% TEAB (5 $\mathrm{min}$ ), then linear gradients from 0 to $100 \%(65 \mathrm{~min})$ of $\left.\mathrm{CH}_{3} \mathrm{CN}\right]$ at a flow rate of $4.0 \mathrm{~mL} / \mathrm{min}$. Dual UV-visible detection was achieved at 210 and $250 \mathrm{~nm}$. 


\section{Synthesis of the chemiluminescent probe 12}

\section{Boc-Asp(TMSE)-OBn: ${ }^{3}$}<smiles></smiles><smiles>CCCOC(=O)C[C@H](NC(=O)[O-])C(=O)O</smiles>

Boc-Asp-OBn (2.04 g, $6.3 \mathrm{mmol})$ was dissolved in a mixture of dry $\mathrm{CH}_{3} \mathrm{CN}(8 \mathrm{~mL})$ and DMF $(1 \mathrm{~mL})$. To this solution was added dry pyridine $(1.02 \mathrm{~mL}, 12.6 \mathrm{mmol}, 2$ eq.) and 2(trimethylsilyl)ethanol (1.08 mL, $7.56 \mathrm{mmol}, 1.2$ eq.). The mixture was cooled to $0^{\circ} \mathrm{C}$, then $N, N$ '-dicyclohexylcarbodiimide $(1.43 \mathrm{~g}, 6.93 \mathrm{mmol}, 1.1 \mathrm{eq}$.$) was added and the reaction$ mixture was stirred overnight at room temperature. Oxalic acid (5M in DMF, $185 \mu \mathrm{L})$ was added and the mixture was stirred for $20 \mathrm{~min}$. The DCU precipitate was removed by filtration, washed with AcOEt and the filtrate was evaporated to dryness. The resulting oily residue was dissolved in $130 \mathrm{~mL}$ of AcOEt and washed successively with a sat. solution of $\mathrm{NaHCO}_{3}$, deionized water, aq. citric acid (10\%) and again with deionized water (60 mL each). The organic layer was dried over $\mathrm{Na}_{2} \mathrm{SO}_{4}$, filtered and concentrated under reduced pressure. The crude product was chromatographed on silica gel $\left(100 \% \mathrm{CH}_{2} \mathrm{Cl}_{2}\right)$, yielding Boc-Asp(TMSE)OBn as a colorless oil (2.66 g, quantitative yield).

${ }^{1} \mathrm{H}$ NMR (300 MHz, $\left.\mathrm{CDCl}_{3}\right): \delta 0.02\left(\mathrm{~s}, 9 \mathrm{H}, \mathrm{Si}\left(\mathrm{CH}_{3}\right)_{3}\right), 0.93\left(\mathrm{t}, J=9.0 \mathrm{~Hz}, 2 \mathrm{H}, \mathrm{CH}_{2} \mathrm{Si}\right), 1.43(\mathrm{~s}$, $\left.9 \mathrm{H}, \mathrm{C}\left(\mathrm{CH}_{3}\right)_{3}\right), 2.79\left(\mathrm{dd}, J=4.5 \mathrm{~Hz}, J=17.0 \mathrm{~Hz}, 1 \mathrm{H}, \mathrm{CH}_{2}\right), 3.00(\mathrm{dd}, J=4.5 \mathrm{~Hz}, J=17.0 \mathrm{~Hz}$, $\left.1 \mathrm{H}, \mathrm{CH}_{2}\right), 4.11\left(\mathrm{t}, J=9.0 \mathrm{~Hz}, 2 \mathrm{H}, \mathrm{OCH}_{2}\right), 4.57-4.63(\mathrm{~m}, 1 \mathrm{H}, \mathrm{CH}), 5.18(\mathrm{dd}, J=7.0 \mathrm{~Hz}, J=$ $\left.12.0 \mathrm{~Hz}, 2 \mathrm{H}, \mathrm{OCH}_{2} \mathrm{Ar}\right), 5.52(\mathrm{~d}, J=9.0 \mathrm{~Hz}, 1 \mathrm{H}, \mathrm{NH}), 7.34(\mathrm{~s}, 5 \mathrm{H}, \mathrm{ArH}) ;{ }^{13} \mathrm{C} \mathrm{NMR}(75.4 \mathrm{MHz}$, $\mathrm{CDCl}_{3}$ ): $\delta-1.2(3 \mathrm{C}), 17.5,28.6(3 \mathrm{C}), 37.2,50.4,63.7,67.7,80.4,128.5-128.8$ (3 peaks, 5C), 135.6, 155.7, 171.3 (2C); IR (neat): 3376, 2955, 2899, $1724 \mathrm{~cm}^{-1} ; \mathrm{R}_{f} 0.5\left(100 \% \mathrm{CH}_{2} \mathrm{Cl}_{2}\right)$; $[\alpha]^{21}{ }_{365}+12.7^{\circ}\left(c 0.98, \mathrm{CHCl}_{3}\right)$; MS (ESI, positive mode): calcd for $\left[\mathrm{C}_{21} \mathrm{H}_{33} \mathrm{NO}_{6} \mathrm{SiNa}\right]^{+} 446.20$, found 446.33; Anal. Calcd for $\mathrm{C}_{21} \mathrm{H}_{33} \mathrm{NO}_{6} \mathrm{Si}$ : C, 59.55; H, 7.85; N, 3.31. Found: C, 59.41; H, 7.76; N, 3.33.

\section{Boc-Glu(TMSE)-OBn:}<smiles>CC(C)(C)NC(=O)[C@H](CCC(=O)O)C(=O)OCc1ccccc1</smiles>
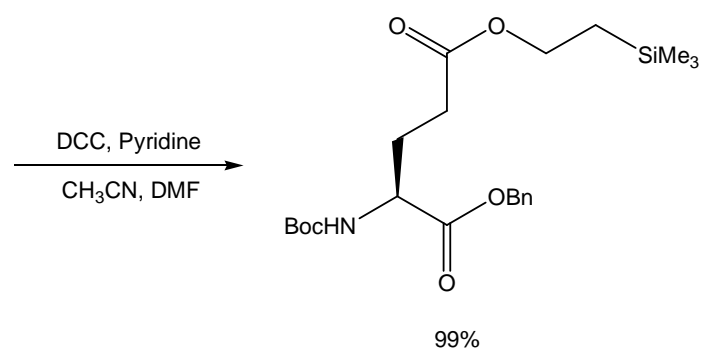

Boc-Glu-OBn (1 g, $2.96 \mathrm{mmol})$ was dissolved in $3 \mathrm{~mL}$ of $\mathrm{CH}_{3} \mathrm{CN}$. To this solution was added dry pyridine ( $478 \mu \mathrm{L}, 5.92 \mathrm{mmol}, 2$ eq.) and 2-(trimethylsilyl)ethanol (509 $\mu \mathrm{L}, 3.55 \mathrm{mmol}, 1.2$ eq.). The mixture was cooled at $0^{\circ} \mathrm{C}$, then $N, N^{\prime}$-dicyclohexylcarbodiimide $(672 \mathrm{mg}, 3.26 \mathrm{mmol}$,

\footnotetext{
${ }^{3}$ Olsen, R. K.; Ramasamy, K.; Emery, T., J. Org. Chem. 1984, 49, 3527-3534.
} 
1.1 eq.) was added and the reaction mixture was stirred at room temperature overnight. Oxalic acid (5M in DMF, $90 \mu \mathrm{L}$ ) was added and the mixture was stirred for $20 \mathrm{~min}$. The DCU precipitate was removed by filtration, washed with AcOEt and the filtrate was evaporated to dryness. The resulting oily residue was dissolved in $70 \mathrm{~mL}$ of AcOEt and washed successively with a sat. solution of $\mathrm{NaHCO}_{3}$, deionized water, citric acid (10\%) and again with deionized water $\left(35 \mathrm{~mL}\right.$ each). The organic layer was dried over $\mathrm{Na}_{2} \mathrm{SO}_{4}$, filtered and concentrated under reduced pressure. The crude product was chromatographed on silica gel $\left(\mathrm{CH}_{2} \mathrm{Cl}_{2} / \mathrm{AcOEt} 95 / 5\right)$, yielding Boc-Glu(TMSE)-OBn as a colorless oil (1.29 g, quantitative yield).

${ }^{1} \mathrm{H}$ NMR $\left(300 \mathrm{MHz}, \mathrm{CDCl}_{3}\right): \delta 0.03\left(\mathrm{~s}, 9 \mathrm{H}, \mathrm{Si}\left(\mathrm{CH}_{3}\right)_{3}\right), 0.95\left(\mathrm{t}, J=7.0 \mathrm{~Hz}, 2 \mathrm{H}, \mathrm{CH}_{2} \mathrm{Si}\right), 1.43(\mathrm{~s}$, $\left.9 \mathrm{H}, \mathrm{C}\left(\mathrm{CH}_{3}\right)_{3}\right), 1.91-1.96\left(\mathrm{~m}, 1 \mathrm{H}, \mathrm{CH}_{2}\right), 2.15-2.19\left(\mathrm{~m}, 1 \mathrm{H}, \mathrm{CH}_{2}\right), 2.27-2.42\left(\mathrm{~m}, 2 \mathrm{H}, \mathrm{CH}_{2} \mathrm{CO}\right)$, $4.14\left(\mathrm{t}, J=7.0 \mathrm{~Hz}, 2 \mathrm{H}, \mathrm{OCH}_{2}\right), 4.35-4.41(\mathrm{~m}, 1 \mathrm{H}, \mathrm{CH}), 5.10(\mathrm{~d}, J=9.0 \mathrm{~Hz}, 1 \mathrm{H}, \mathrm{NH}), 5.17(\mathrm{~s}$, $2 \mathrm{H}, \mathrm{OCH}_{2} \mathrm{Ar}$ ), 7.35 (s, 5H, $\left.\mathrm{ArH}\right) ;{ }^{13} \mathrm{C}$ NMR $\left(75.4 \mathrm{MHz}, \mathrm{CDCl}_{3}\right): \delta-1.3(3 \mathrm{C}), 17.5,27.9,28.5$ (3C), 30.7, 53.3, 63.1, 67.4, 80.2, 128.5-128.9 (5C), 135.5, 155.6, 172.4, 173.0; IR (neat): 3371, 2955, 2899, $1732 \mathrm{~cm}^{-1} ;[\alpha]^{21}{ }_{365}+4.6^{\circ}\left(\mathrm{c} 1.12, \mathrm{CHCl}_{3}\right) ; \mathrm{R}_{f} 0.5\left(\mathrm{CH}_{2} \mathrm{Cl}_{2} / \mathrm{AcOEt}\right.$ 95/5); MS (ESI, positive mode): calcd for $\left[\mathrm{C}_{22} \mathrm{H}_{35} \mathrm{NO}_{6} \mathrm{SiNa}\right]^{+} 460.21$, found 460.27; Anal. Calcd. for $\mathrm{C}_{22} \mathrm{H}_{35} \mathrm{NO}_{6} \mathrm{Si}: \mathrm{C}, 60.38 ; \mathrm{H}, 8.06 ; \mathrm{N}, 3.20$. Found: C, 60.36; H, 8.02; N, 3.44.

\section{Boc-Asp(TMSE)-OH:}

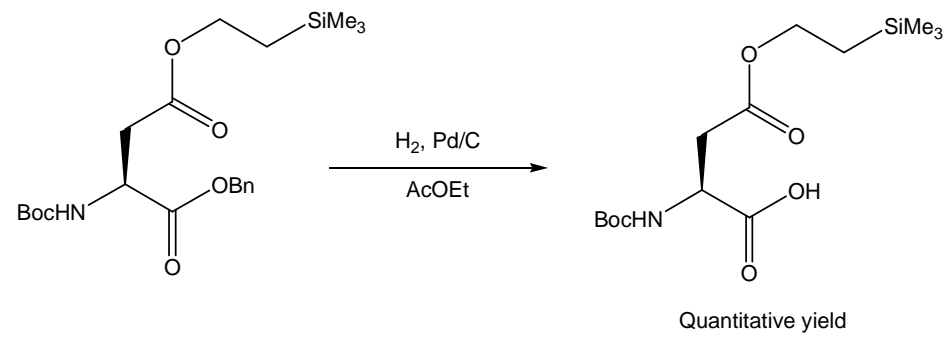

Boc-Asp(TMSE)-OBn (1.24 g, $2.9 \mathrm{mmol})$ was dissolved in AcOEt (50 mL). The solution was cooled to $0^{\circ} \mathrm{C}$ and $\mathrm{Pd} / \mathrm{C}$ catalyst $(10 \%, 120 \mathrm{mg})$ was added. Then, the reaction mixture was put under an hydrogen atmosphere and stirred at room temperature overnight. The $\mathrm{Pd} / \mathrm{C}$ catalyst was removed by filtration through a Celite ${ }^{\circledR} 545 \mathrm{pad}$, and the filtrate was concentrated under vacuum, yielding Boc-Asp(TMSE)-OH as colorless crystals (977 mg, quantitative yield).

${ }^{1} \mathrm{H}$ NMR (300 MHz, $\left.\mathrm{CDCl}_{3}\right): \delta 0.03\left(\mathrm{~s}, 9 \mathrm{H}, \mathrm{Si}\left(\mathrm{CH}_{3}\right)_{3}\right), 0.98\left(\mathrm{t}, J=7.0 \mathrm{~Hz}, 2 \mathrm{H}, \mathrm{CH}_{2} \mathrm{Si}\right), 1.43(\mathrm{~s}$, $\left.9 \mathrm{H}, \mathrm{C}\left(\mathrm{CH}_{3}\right)_{3}\right), 2.80\left(\mathrm{dd}, J=5.0 \mathrm{~Hz}, J=17.0 \mathrm{~Hz}, 1 \mathrm{H}, \mathrm{CH}_{2}\right), 3.00(\mathrm{dd}, J=4.0 \mathrm{~Hz}, J=17.0 \mathrm{~Hz}$, $\left.1 \mathrm{H}, \mathrm{CH}_{2}\right), 4.18\left(\mathrm{t}, J=7.0 \mathrm{~Hz}, 2 \mathrm{H}, \mathrm{OCH}_{2}\right), 4.58-4.61(\mathrm{~m}, 1 \mathrm{H}, \mathrm{CH}), 5.56(\mathrm{~d}, J=9.0 \mathrm{~Hz}, 1 \mathrm{H}$, $\mathrm{NH}), 11.05\left(\mathrm{~s}_{\text {broad }}, 1 \mathrm{H}, \mathrm{COOH}\right) ;{ }^{13} \mathrm{C} \mathrm{NMR}\left(75.4 \mathrm{MHz}, \mathrm{CDCl}_{3}\right): \delta 1.2(3 \mathrm{C}), 17.6,28.6(3 \mathrm{C})$, 37.0, 50.1, 63.9, 80.7, 155.9, 171.7, 176.5; $[\alpha]^{21}{ }_{365}+106.3^{\circ}\left(c 0.98, \mathrm{CHCl}_{3}\right)$; IR (KBr): 3445, 2956, 1736, 1658, $1519 \mathrm{~cm}^{-1}$; MS (MALDI-TOF, positive mode, CHCA matrix): calcd for $\left[\mathrm{C}_{14} \mathrm{H}_{26} \mathrm{NO}_{6} \mathrm{SiK}\right]^{+}$372.12, found 372.42; Anal. Calcd for $\mathrm{C}_{14} \mathrm{H}_{26} \mathrm{NO}_{6} \mathrm{Si}$ : C, 50.43; H, 8.16; N, 4.20. Found: C, 50.35; H, 8.13; N, 4.21. 


\section{H-Glu(TMSE)-OBn:}
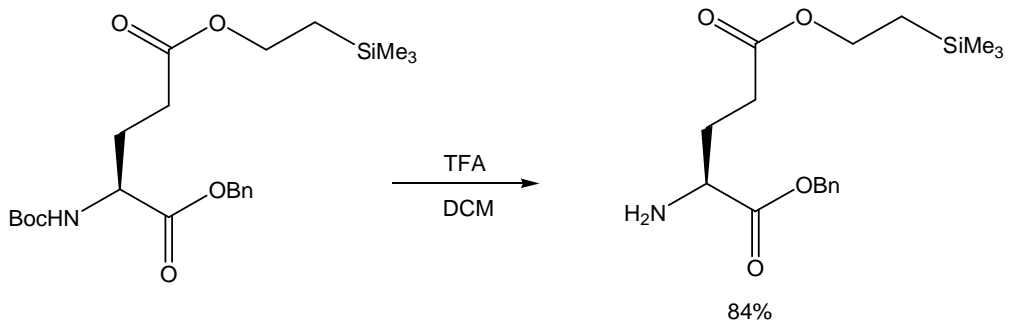

Boc-Glu(TMSE)-OBn (5.19 g, $11.9 \mathrm{mmol})$ was dissolved in dry $\mathrm{CH}_{2} \mathrm{Cl}_{2}$ (140 mL). The solution was cooled to $0^{\circ} \mathrm{C}$ and TFA $(17 \mathrm{~mL}, 237 \mathrm{mmol}, 20$ eq.) was added. The reaction mixture was stirred at room temperature for $2 \mathrm{~h}$. Then, the mixture was cooled to $0^{\circ} \mathrm{C}$ and a solution of sat. $\mathrm{NaHCO}_{3}(250 \mathrm{~mL})$ was added. The aqueous layer was extracted twice with $\mathrm{CH}_{2} \mathrm{Cl}_{2}(100 \mathrm{~mL})$ and the combined organic layers were washed with deionized water (200 $\mathrm{mL}$ ), dried over $\mathrm{Na}_{2} \mathrm{SO}_{4}$, filtered and concentrated under reduced pressure, affording $\mathbf{H}$ Glu(TMSE)-OBn as a yellow oil (3.37 g, 84\%).

${ }^{1} \mathrm{H}$ NMR $\left(300 \mathrm{MHz}, \mathrm{CDCl}_{3}\right): \delta 0.03\left(\mathrm{~s}, 9 \mathrm{H}, \mathrm{Si}\left(\mathrm{CH}_{3}\right)_{3}\right), 0.97\left(\mathrm{t}, J=8.0 \mathrm{~Hz}, 2 \mathrm{H}, \mathrm{CH}_{2} \mathrm{Si}\right), 1.51(\mathrm{~s}$, $\left.2 \mathrm{H}, \mathrm{NH}_{2}\right), 1.81-1.91\left(\mathrm{~m}, 1 \mathrm{H}, \mathrm{CH}_{2}\right), 2.04-2.14\left(\mathrm{~m}, 1 \mathrm{H}, \mathrm{CH}_{2}\right), 2.43\left(\mathrm{t}, J=7.5 \mathrm{~Hz}, 2 \mathrm{H}, \mathrm{CH}_{2} \mathrm{CO}\right)$, 3.49-3.54 (m, $1 \mathrm{H}, \mathrm{CH}), 4.15\left(\mathrm{t}, J=8.0 \mathrm{~Hz}, 2 \mathrm{H}, \mathrm{OCH}_{2}\right), 5.15\left(\mathrm{~s}, 2 \mathrm{H}, \mathrm{OCH}_{2} \mathrm{Ar}\right), 7.35(\mathrm{~s}, 5 \mathrm{H}$, $\mathrm{ArH}) ;{ }^{13} \mathrm{C}$ NMR $\left(75.4 \mathrm{MHz}, \mathrm{CDCl}_{3}\right): \delta-1.2$ (3C), 17.6, 30.0, 31.1, 54.2, 63.0, 67.1, 128.6128.9 (3 peaks, 5C), 135.9, 173.6, 175.8; $\mathrm{R}_{f} 0.5\left(\mathrm{CH}_{2} \mathrm{Cl}_{2} / \mathrm{AcOEt} 1 / 1\right)$; IR (neat) 3323, 3019, 2957, 2898, 1732, $1694 \mathrm{~cm}^{-1}$; $[\alpha]^{21} 365-2.4^{\circ}\left(c\right.$ 1.12, $\left.\mathrm{CHCl}_{3}\right)$; MS (MALDI-TOF, positive mode, CHCA matrix): calcd for $\left[\mathrm{C}_{17} \mathrm{H}_{28} \mathrm{NO}_{4} \mathrm{Si}\right]^{+} 338.18$, found 338.47; Anal. Calcd. for $\mathrm{C}_{16} \mathrm{H}_{25} \mathrm{NO}_{4} \mathrm{Si}$ C, 59.41; H, 7.79; N, 4.33, found C, 59.34; H, 7.39; N, 4.23.

\section{Boc-Asp(TMSE)-Glu(TMSE)-OBn:}
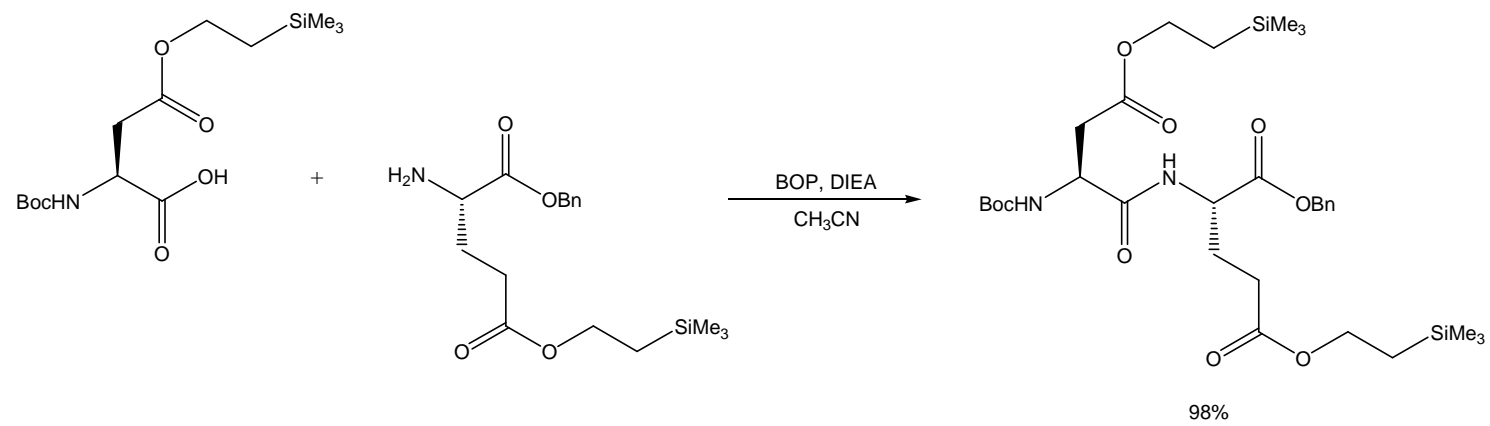

H-Glu(TMSE)-OBn $(3.64 \mathrm{~g}, 10.8 \mathrm{mmol})$ was dissolved in dry $\mathrm{CH}_{3} \mathrm{CN}(35 \mathrm{~mL})$, then BocAsp(TMSE)-OH (3.60 g, $10.8 \quad$ mmol, $1 \quad$ eq. $), \quad$ O-Benzotriazol-1yloxytris(dimethylamino)phosphonium hexafluorophosphate (BOP) (4.77 g, $10.8 \mathrm{mmol}$, 1. eq.) and diisopropylethylamine (DIEA) $(5.35 \mathrm{~mL}, 32.4 \mathrm{mmol}, 3 \mathrm{eq}$.) were sequentially added and the resulting reaction mixture was stirred at room temperature for $45 \mathrm{~min}$. The solvent was removed under vacuum, the resulting oil was dissolved in $\mathrm{CH}_{2} \mathrm{Cl}_{2}(140 \mathrm{~mL})$ and washed with a sat. solution of $\mathrm{NaHCO}_{3}(70 \mathrm{~mL})$. The aqueous layer was extracted with $\mathrm{CH}_{2} \mathrm{Cl}_{2}(100 \mathrm{~mL})$ and the combined organic layers were washed with deionized water $(70 \mathrm{~mL})$, dried over $\mathrm{Na}_{2} \mathrm{SO}_{4}$, filtered and evaporated under reduced pressure. The crude product was chromatographed over silica gel $\left(\mathrm{CH}_{2} \mathrm{Cl}_{2} / \mathrm{AcOEt} 70 / 30\right)$, affording Boc-Asp(TMSE)-Glu(TMSE)-OBn as a yellow oil $(2.18 \mathrm{~g}, 98 \%)$. 
${ }^{1} \mathrm{H}$ NMR $\left(300 \mathrm{MHz}, \mathrm{CDCl}_{3}\right): \delta 0.03\left(\mathrm{~s}, 18 \mathrm{H}, 2 \mathrm{Si}\left(\mathrm{CH}_{3}\right)_{3}\right), 0.93-1.01\left(\mathrm{~m}, 4 \mathrm{H}, 2 \mathrm{CH}_{2} \mathrm{Si}\right), 1.45(\mathrm{~s}$, $\left.9 \mathrm{H}, \mathrm{C}\left(\mathrm{CH}_{3}\right)_{3}\right), 1.97-2.04\left(\mathrm{~m}, 1 \mathrm{H}, \mathrm{CH}_{2 G l u}\right), 2.19-2.37\left(\mathrm{~m}, 3 \mathrm{H}, \mathrm{CH}_{2} \mathrm{CO}_{\text {Glu }}+\mathrm{CH}_{2 G l u}\right), 2.62(\mathrm{dd}, \mathrm{J}=$ $\left.6.0 \mathrm{~Hz}, J=17.0 \mathrm{~Hz}, 1 \mathrm{H}, \mathrm{CH}_{2 A s p}\right), 2.99\left(\mathrm{dd}, J=5.0 \mathrm{~Hz}, J=17 \mathrm{~Hz}, 1 \mathrm{H}, \mathrm{CH}_{2 A s p}\right), 4.11-4.20(\mathrm{~m}$, $\left.4 \mathrm{H}, \mathrm{OCH}_{2}\right), 4.46-4.54\left(\mathrm{~m}, 1 \mathrm{H}, \mathrm{C}^{*} H_{\text {Asp }}\right), 4.59-4.66\left(\mathrm{~m}, 1 \mathrm{H}, \mathrm{C}^{*} H_{G l u}\right), 5.16\left(\mathrm{~s}, 2 \mathrm{H}, \mathrm{OCH}_{2} \mathrm{Ar}\right), 5.68$ $\left(\mathrm{d}, J=8.0 \mathrm{~Hz}, 1 \mathrm{H}, \mathrm{N} H_{A s p}\right), 7.18\left(\mathrm{~d}, J=8.0 \mathrm{~Hz}, 1 \mathrm{H}, \mathrm{N} H_{G l u}\right), 7.34(\mathrm{~s}, 5 \mathrm{H}, \mathrm{ArH}) ;{ }^{13} \mathrm{C} \mathrm{NMR}(75.4$ $\left.\mathrm{MHz} \mathrm{CDCl}_{3}\right): \delta-1.2(6 \mathrm{C}), 17.6(2 \mathrm{C}), 27.7,28.6(3 \mathrm{C}), 30.4,36.5,50.8,52.1,63.2,63.7,67.6$, 80.8, 128.5-128.9 (3 peaks, 5C), 135.5, 171.1, 171.6, 172.5, 173.1; IR (neat): 3350, 2955, 2899, $1732,1682 \mathrm{~cm}^{-1} ;[\alpha]^{21}{ }_{365}+44.7^{\circ}\left(c\right.$ 1.06, $\left.\mathrm{CHCl}_{3}\right) ; \mathrm{R}_{f} 0.5\left(\mathrm{CH}_{2} \mathrm{Cl}_{2} / \mathrm{AcOEt} 7 / 3\right)$; MS (MALDITOF, positive mode, CHCA matrix): calcd for $\left[\mathrm{C}_{31} \mathrm{H}_{52} \mathrm{~N}_{2} \mathrm{O}_{9} \mathrm{Si}_{2} \mathrm{Na}\right]^{+}$675.31, found 675.62; Anal. Calcd for $\mathrm{C}_{31} \mathrm{H}_{52} \mathrm{~N}_{2} \mathrm{O}_{9} \mathrm{Si}_{2}:$ C, 57.03; H, 8.03; N, 4.29. Found: C, 57.13; H, 7.71; N, 4.26.

\section{H-Asp(TMSE)-Glu(TMSE)-OBn (TFA salt):}
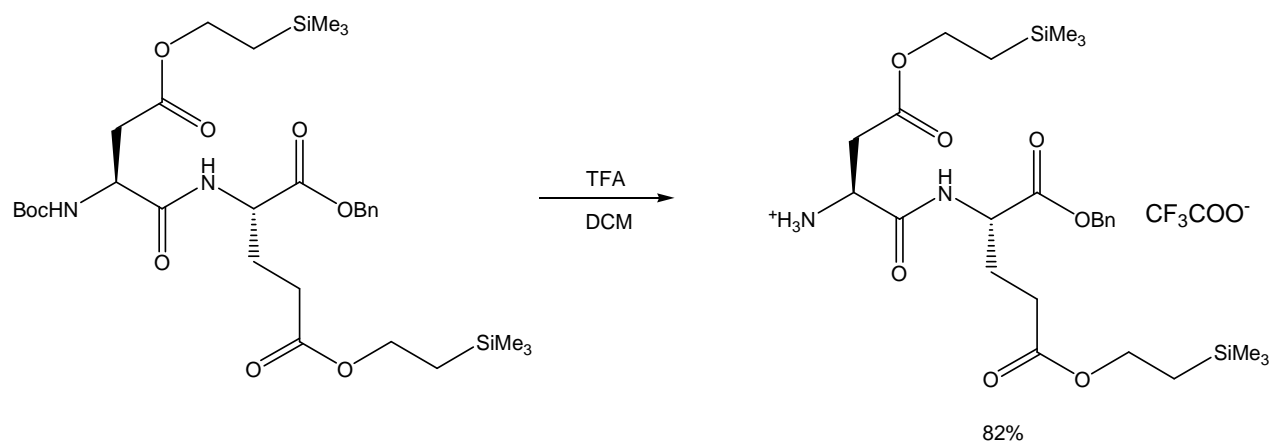

Boc-Asp(TMSE)-Glu(TMSE)-OBn (1.32 g, $2.03 \mathrm{mmol})$ was dissolved in dry $\mathrm{CH}_{2} \mathrm{Cl}_{2}(30$ $\mathrm{mL}$ ). The solution was cooled to $0^{\circ} \mathrm{C}$ and TFA ( $3 \mathrm{~mL}, 40.6 \mathrm{mmol}, 20$ eq.) was added. The mixture was stirred at room temperature for $2.5 \mathrm{~h}$, then the solution was cooled to $0^{\circ} \mathrm{C}, \mathrm{AcOEt}$ $(40 \mathrm{~mL})$ and a sat. solution of $\mathrm{NaHCO}_{3}(40 \mathrm{~mL})$ were added. The phases were separated and the aqueous layer was extracted twice with AcOEt $(30 \mathrm{~mL})$. The combined organic layers were washed with deionized water $(50 \mathrm{~mL})$, dried over $\mathrm{Na}_{2} \mathrm{SO}_{4}$ and filtered. Then, TFA $(180 \mu \mathrm{L}, 2.4$ mmol, 1.2 eq.) was added and the organic layer was evaporated under reduced pressure, affording TFA salt of H-Asp(TMSE)-Glu(TMSE)-OBn as a yellow oil (1.11 g, 82\%).

${ }^{1} \mathrm{H}$ NMR (300 MHz, $\left.\mathrm{CDCl}_{3}\right): \delta 0.02\left(\mathrm{~s}, 9 \mathrm{H}, \mathrm{Si}\left(\mathrm{CH}_{3}\right)_{3}\right), 0.03\left(\mathrm{~s}, 9 \mathrm{H}, \mathrm{Si}\left(\mathrm{CH}_{3}\right)_{3}\right), 0.91-1.02(\mathrm{~m}$, $\left.4 \mathrm{H}, 2 \mathrm{CH}_{2} \mathrm{Si}\right), 1.97-2.23\left(\mathrm{~m}, 2 \mathrm{H}, \mathrm{CH}_{2 G l u}\right), 2.33\left(\mathrm{t}, J=7.0 \mathrm{~Hz}, 2 \mathrm{H}, \mathrm{CH}_{2} \mathrm{CO}_{\text {Glu }}\right), 2.93(\mathrm{~d}, J=7.0$ $\left.\mathrm{Hz}, 2 \mathrm{H}, \mathrm{CH}_{2 A s p}\right), 4.10-4.24\left(\mathrm{~m}, 4 \mathrm{H}, \mathrm{OCH}_{2}\right), 4.49\left(\mathrm{t}, J=7.0 \mathrm{~Hz}, 1 \mathrm{H}, \mathrm{C}^{*} H_{A s p}\right), 4.52-4.60(\mathrm{~m}, 1 \mathrm{H}$, $\left.\mathrm{C}^{*} H_{G l u}\right), 5.14\left(\mathrm{dd}, J=12.0 \mathrm{~Hz}, J=24.0 \mathrm{~Hz}, 2 \mathrm{H}, \mathrm{OCH}_{2} \mathrm{Ar}\right), 7.33(\mathrm{~s}, 5 \mathrm{H}, \mathrm{ArH}), 7.95(\mathrm{~d}, J=8.0$ $\left.\mathrm{Hz}, 1 \mathrm{H}, \mathrm{N} H_{G l u}\right) ;{ }^{13} \mathrm{C}$ NMR $\left(75.4 \mathrm{MHz}, \mathrm{CDCl}_{3}\right): \delta-1.4(3 \mathrm{C}),-1.3(3 \mathrm{C}), 17.4(2 \mathrm{C}), 26.8,30.5$, 35.2, 50.1, 52.6, 63.8, 65.1, 67.9, 128.6-129.0 (3 peaks, 5C), 135.2, 168.6, 171.0, 171.4, 174.1; IR (neat): 3361, 2954, 2886, 2360, 1737, 1682, $1506 \mathrm{~cm}^{-1} ;[\alpha]^{21}{ }_{365}+5.1^{\circ}\left(c 1.01, \mathrm{CHCl}_{3}\right) ; \mathrm{R}_{f}$ $0.5\left(\mathrm{CH}_{2} \mathrm{Cl}_{2} / \mathrm{AcOEt} 1 / 1\right)$; MS (MALDI-TOF, positive mode, CHCA matrix): calcd for $\left[\mathrm{C}_{26} \mathrm{H}_{44} \mathrm{~N}_{2} \mathrm{O}_{7} \mathrm{Si}_{2} \mathrm{Na}\right]^{+}$575.26, found 575.46. 


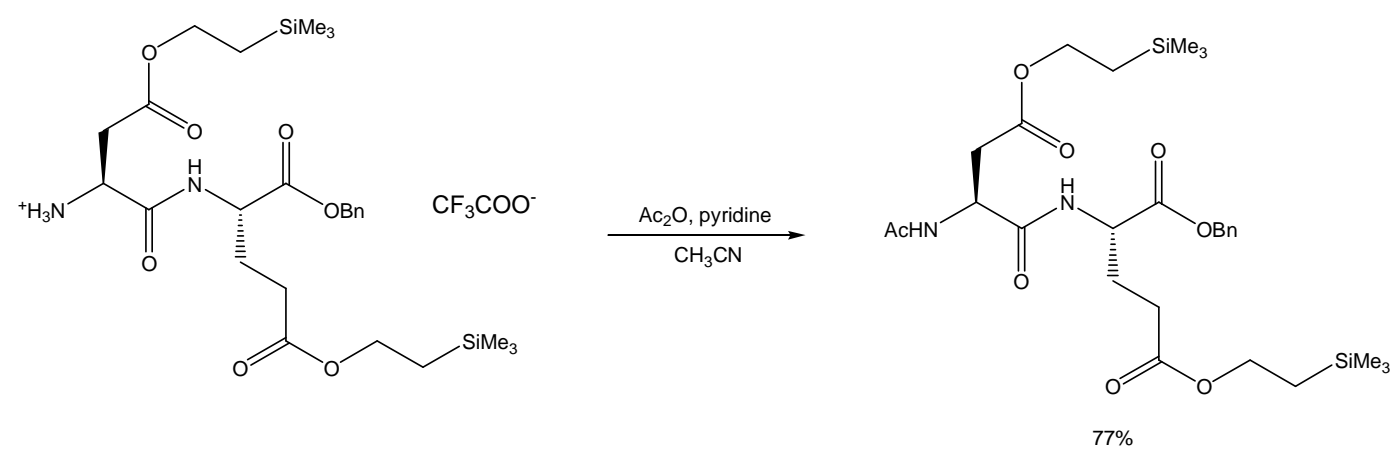

TFA.H-Asp(TMSE)-Glu(TMSE)-OBn (892 mg, $1.34 \mathrm{mmol})$ was dissolved in dry $\mathrm{CH}_{3} \mathrm{CN}$ (7 $\mathrm{mL})$. Then, acetic anhydride $(505 \mu \mathrm{L}, 5.35 \mathrm{mmol}, 4$ eq. $)$ and dry pyridine $(650 \mu \mathrm{L}, 8.04 \mathrm{mmol}$, 6 eq.) were added and the solution was stirred at room temperature for $1 \mathrm{~h}$. EtOH $(500 \mu \mathrm{L})$ was added and the mixture was stirred for $20 \mathrm{~min}$, allowing the conversion of the excess of acetic anhydride in AcOEt. The reaction mixture was concentrated to dryness and the resulting oily residue was dissolved in $\mathrm{CH}_{2} \mathrm{Cl}_{2}(50 \mathrm{~mL})$. The organic layer was successively washed with aq. citric acid (10\%), deionized water, sat. $\mathrm{NaHCO}_{3}$ and deionized water $(20 \mathrm{~mL}$ each). The combined organic layer were dried over $\mathrm{Na}_{2} \mathrm{SO}_{4}$, filtered and concentrated under reduced pressure, affording Ac-Asp(TMSE)-Glu(TMSE)-OBn as a colorless oil which quickly crystallizes $(617 \mathrm{mg}, 77 \%)$.

${ }^{1} \mathrm{H} \mathrm{NMR}\left(300 \mathrm{MHz}, \mathrm{CDCl}_{3}\right): \delta 0.03\left(\mathrm{~s}, 18 \mathrm{H}, 2 \mathrm{Si}\left(\mathrm{CH}_{3}\right)_{3}\right), 0.93-1.02\left(\mathrm{~m}, 4 \mathrm{H}, 2 \mathrm{CH}_{2} \mathrm{Si}\right), 1.90-2.04$ $\left(\mathrm{m}, 4 \mathrm{H}, \mathrm{CH}_{3}+\mathrm{CH}_{2 G l u}\right), 2.1-2.4\left(\mathrm{~m}, 4 \mathrm{H}, \mathrm{CH}_{2} \mathrm{CO}_{G l u}+\mathrm{CH}_{2 G l u}\right), 2.57(\mathrm{dd}, J=6.0 \mathrm{~Hz}, J=17.0 \mathrm{~Hz}$, $\left.1 \mathrm{H}, \mathrm{CH}_{2 A s p}\right), 2.98$ (dd, $J=4.0 \mathrm{~Hz}, J=17 \mathrm{~Hz}, 1 \mathrm{H}, \mathrm{CH}_{2 A s p}$ ), 4.11-4.21 (m, 4H, OCH $\mathrm{OH}_{2}$, 4.52-4.62 $\left(\mathrm{m}, 1 \mathrm{H}, \mathrm{C}^{*} H_{G l u}\right), 4.77-4.87\left(\mathrm{~m}, 1 \mathrm{H}, \mathrm{C}^{*} H_{A s p}\right), 5.15\left(\mathrm{dd}, J=12.0 \mathrm{~Hz}, J=2.0 \mathrm{~Hz}, 2 \mathrm{H}, \mathrm{OCH}_{2} \mathrm{Ar}\right)$, $6.78\left(\mathrm{~d}, J=8 \mathrm{~Hz}, 1 \mathrm{H}, \mathrm{NH}_{A s p}\right), 7.34(\mathrm{~s}, 5 \mathrm{H}, \mathrm{ArH}) ;{ }^{13} \mathrm{C} \mathrm{NMR}\left(75.4 \mathrm{MHz}, \mathrm{CDCl}_{3}\right): \delta-1.2(6 \mathrm{C})$, 17.5, 17.6, 23.6, 27.2 , 30.6, 36.2, 49.4, 52.4, 63.4, 63.9, 67.6, 128.6-129.0 (3 peaks, 5C), 135.5, 170.4, 170.9, 171.4, 172.8, 173.3; $\mathrm{R}_{f} 0.5\left(\mathrm{CH}_{2} \mathrm{Cl}_{2} / \mathrm{AcOEt} 7 / 3\right)$; IR (KBr): 3290, 2955, 1733 , 1643, $1557 \mathrm{~cm}^{-1} ;[\alpha]^{21}{ }_{436}+5.5^{\circ}\left(c \quad 0.95, \mathrm{CHCl}_{3}\right)$; MS (MALDI-TOF, positive mode, CHCA matrix): calcd for $\left[\mathrm{C}_{28} \mathrm{H}_{46} \mathrm{~N}_{2} \mathrm{O}_{8} \mathrm{Si}_{2} \mathrm{Na}\right]^{+}$617.27, found 617.63; Anal. Calcd for $\mathrm{C}_{28} \mathrm{H}_{46} \mathrm{~N}_{2} \mathrm{O}_{8} \mathrm{Si}_{2}$ : C, 56.54; H, 7.79; N, 4.71. Found: C, 56.63; H, 7.65; N, 4.52 .

\section{Ac-Asp(TMSE)-Glu(TMSE)-OH:}
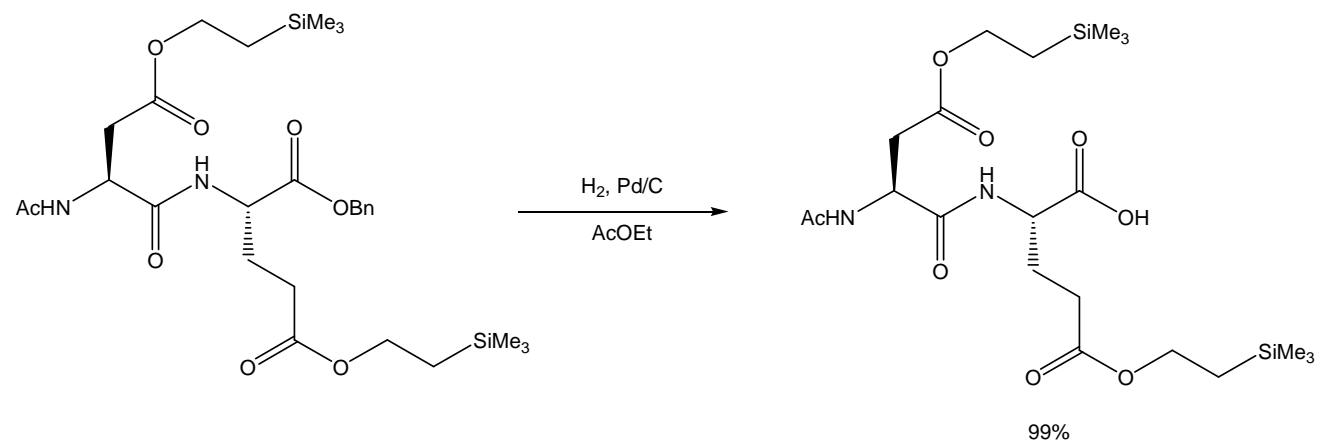

Ac-Asp(TMSE)-Glu(TMSE)-OBn (608 mg, $1.03 \mathrm{mmol}$ ) was dissolved in AcOEt (50 mL). The solution was cooled to $0^{\circ} \mathrm{C}$ and $\mathrm{Pd} / \mathrm{C}$ catalyst $(10 \%, 47 \mathrm{mg})$ was added. Then, the reaction 
mixture was put under an hydrogen atmosphere and stirred at room temperature overnight. The $\mathrm{Pd} / \mathrm{C}$ catalyst was removed by filtration through a Celite ${ }^{\circledR} 545 \mathrm{pad}$, and the filtrate was concentrated under vacuum, yielding Ac-Asp(TMSE)-Glu(TMSE)-OH as a colorless oil (515 mg, quantitative yield).

${ }^{1} \mathrm{H}$ NMR (300 MHz, $\left.\mathrm{CDCl}_{3}\right): \delta 0.03\left(\mathrm{~s}, 9 \mathrm{H}, \mathrm{Si}\left(\mathrm{CH}_{3}\right)_{3}\right), 0.06\left(\mathrm{~s}, 9 \mathrm{H}, \mathrm{Si}\left(\mathrm{CH}_{3}\right)_{3}\right), 0.96-1.02(\mathrm{~m}$, $\left.4 \mathrm{H}, 2 \mathrm{CH}_{2} \mathrm{Si}\right), 1.96-2.10\left(\mathrm{~m}, 4 \mathrm{H}, \mathrm{CH}_{3}+\mathrm{CH}_{2 G l u}\right), 2.15-2.30\left(\mathrm{~m}, 1 \mathrm{H}, \mathrm{CH}_{2 \mathrm{Glu}}\right), 2.32-2.51(\mathrm{~m}, 2 \mathrm{H}$, $\left.\mathrm{CH}_{2} \mathrm{CO}_{G l u}\right), 2.63\left(\mathrm{dd}, J=6.0 \mathrm{~Hz}, J=17.0 \mathrm{~Hz}, 1 \mathrm{H}, \mathrm{CH}_{2 A s p}\right), 2.98(\mathrm{dd}, J=4.0 \mathrm{~Hz}, J=17.0 \mathrm{~Hz}$, $\left.1 \mathrm{H}, \mathrm{C} H_{2 A s p}\right), 4.09-4.22\left(\mathrm{~m}, 4 \mathrm{H}, \mathrm{OCH}_{2}\right), 4.46-4.53\left(\mathrm{~m}, 1 \mathrm{H}, \mathrm{C}^{*} H_{G l u}\right), 4.83-4.89\left(\mathrm{~m}, 1 \mathrm{H}, \mathrm{C}^{*} H_{A s p}\right)$, $7.03\left(\mathrm{~d}, J=8.0 \mathrm{~Hz}, 1 \mathrm{H}, \mathrm{N} H_{A s p}\right), 7.56\left(\mathrm{~d}, J=8.0 \mathrm{~Hz}, 1 \mathrm{H}, \mathrm{N} H_{G l u}\right) ;{ }^{13} \mathrm{C} \mathrm{NMR}\left(75.4 \mathrm{MHz}, \mathrm{CDCl}_{3}\right)$ : $\delta-1.17$ (6C), 17.5, 17.6, 23.5, 26.8, 30.9, 36.1, 49.6, 52.6, 63.5, 64.0, 171.3, 171.4, 172.7, 173.9, 174.0; IR (neat): 3308, 2954, 1733, 1656, $1536 \mathrm{~cm}^{-1} ;[\alpha]^{21}{ }_{365}+32.1^{\circ}\left(c 0.39, \mathrm{CHCl}_{3}\right) ; \mathrm{R}_{f}$ 0.2 (100\% AcOEt); MS (MALDI-TOF, positive mode, CHCA matrix): calcd for $\left[\mathrm{C}_{21} \mathrm{H}_{40} \mathrm{~N}_{2} \mathrm{O}_{8} \mathrm{Si}_{2} \mathrm{Na}\right]^{+}$527.22, found 527.58; Anal Calcd for $\mathrm{C}_{21} \mathrm{H}_{40} \mathrm{~N}_{2} \mathrm{O}_{8} \mathrm{Si}_{2}, 0.14 \mathrm{CH}_{2} \mathrm{Cl}_{2}: \mathrm{C}_{\text {, }}$ 49.13; H, 7.86; N, 5.42. Found: C, 48.87; H, 7.84; N, 5.50.

\section{H-Glu(TMSE)-OBn:}
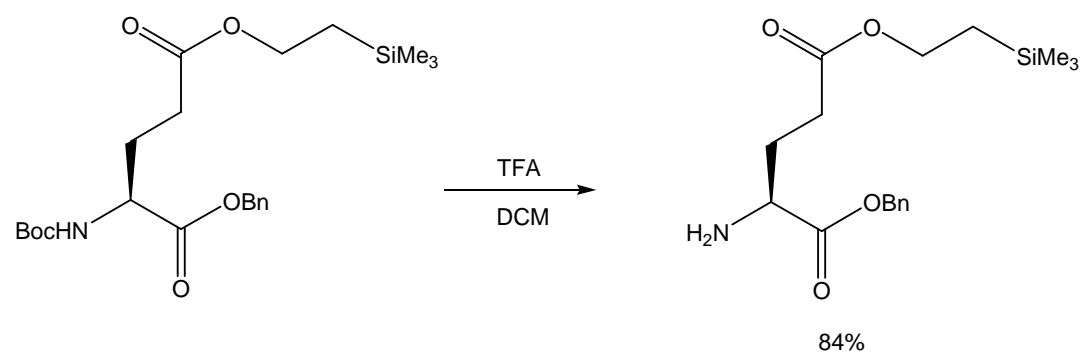

Boc-Glu(TMSE)-OBn (5.19 g, $11.9 \mathrm{mmol})$ was dissolved in dry $\mathrm{CH}_{2} \mathrm{Cl}_{2}(140 \mathrm{~mL})$. The solution was cooled to $0^{\circ} \mathrm{C}$ and TFA $(17 \mathrm{~mL}, 237 \mathrm{mmol}, 20$ eq. $)$ was added. The reaction mixture was stirred at room temperature for $2 \mathrm{~h}$. Thereafter, the mixture was cooled to $0^{\circ} \mathrm{C}$ and a solution of sat. $\mathrm{NaHCO}_{3}(250 \mathrm{~mL})$ was added. The aqueous layer was extracted twice with $\mathrm{CH}_{2} \mathrm{Cl}_{2}(100 \mathrm{~mL})$ and the combined organic phases were washed with deionized water (200 $\mathrm{mL}$ ), dried over $\mathrm{Na}_{2} \mathrm{SO}_{4}$, filtered and concentrated under reduced pressure, affording $\mathbf{H}$ Glu(TMSE)-OBn as a yellow oil (3.37 g, 84\%).

${ }^{1} \mathrm{H}$ NMR $\left(300 \mathrm{MHz}, \mathrm{CDCl}_{3}\right): \delta 0.03\left(\mathrm{~s}, 9 \mathrm{H}, \mathrm{Si}\left(\mathrm{CH}_{3}\right)_{3}\right), 0.97\left(\mathrm{t}, J=8.0 \mathrm{~Hz}, 2 \mathrm{H}, \mathrm{CH}_{2} \mathrm{Si}\right), 1.51(\mathrm{~s}$, 2H, $\left.\mathrm{NH}_{2}\right), 1.81-1.91\left(\mathrm{~m}, 1 \mathrm{H}, \mathrm{CH}_{2}\right), 2.04-2.14\left(\mathrm{~m}, 1 \mathrm{H}, \mathrm{CH}_{2}\right), 2.43\left(\mathrm{t}, \mathrm{J}=7.5 \mathrm{~Hz}, 2 \mathrm{H}, \mathrm{CH}_{2} \mathrm{CO}\right)$, 3.49-3.54 (m, 1H, CH), $4.15\left(\mathrm{t}, J=8.0 \mathrm{~Hz}, 2 \mathrm{H}, \mathrm{OCH}_{2}\right), 5.15\left(\mathrm{~s}, 2 \mathrm{H}, \mathrm{OCH}_{2} \mathrm{Ar}\right), 7.35(\mathrm{~s}, 5 \mathrm{H}$, $\mathrm{ArH}) ;{ }^{13} \mathrm{C}$ NMR $\left(75.4 \mathrm{MHz}, \mathrm{CDCl}_{3}\right): \delta$-1.2 (3C), 17.6, 30.0, 31.1, 54.2, 63.0, 67.1, 128.6128.9 (3 peaks, 5C), 135.9, 173.6, 175.8; $\mathrm{R}_{f} 0.5\left(\mathrm{CH}_{2} \mathrm{Cl}_{2} / \mathrm{AcOEt} 1 / 1\right)$; IR (neat) 3323, 3019, 2957, 2898, 1732, $1694 \mathrm{~cm}^{-1}$; $[\alpha]^{21}{ }_{365}-2.4^{\circ}\left(c\right.$ 1.12, $\left.\mathrm{CHCl}_{3}\right)$; MS (MALDI-TOF, positive mode, CHCA matrix): calcd for $\left[\mathrm{C}_{17} \mathrm{H}_{28} \mathrm{NO}_{4} \mathrm{Si}\right]^{+} 338.18$, found 338.47; Anal. Calcd. for $\mathrm{C}_{16} \mathrm{H}_{25} \mathrm{NO}_{4} \mathrm{Si}$ C, 59.41; H, 7.79; N, 4.33, found C, 59.34; H, 7.39; N, 4.23. 


\section{Boc-Val-Asp(TMSE)-OBn:}

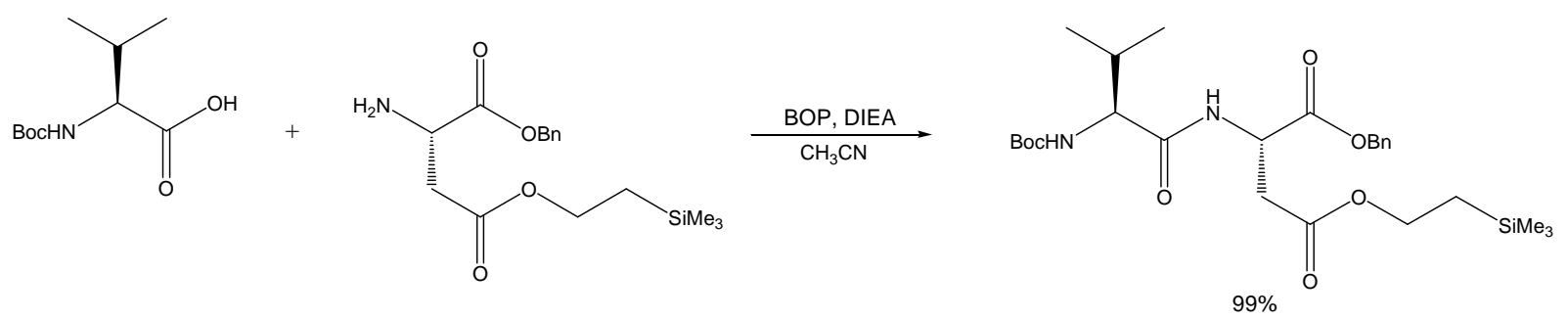

H-Asp(TMSE)-OBn (719 mg, $2.22 \mathrm{mmol}$ ) was dissolved in dry $\mathrm{CH}_{3} \mathrm{CN}$ (12 mL) and BocVal-OH (487 mg, $2.24 \mathrm{mmol}, 1.01$ eq.), BOP reagent (991 mg, $2.24 \mathrm{mmol}, 1$ eq.) and DIEA $(1.16 \mathrm{~mL}, 6.66 \mathrm{mmol}, 3 \mathrm{eq}$.) were sequentially added. The resulting reaction mixture was stirred at room temperature for $2 \mathrm{~h}$. The solvent was removed under vacuum, the resulting oily residue was dissolved in $\mathrm{CH}_{2} \mathrm{Cl}_{2}(65 \mathrm{~mL})$ and washed with a sat. solution of $\mathrm{NaHCO}_{3}(30 \mathrm{~mL})$. The aqueous layer was extracted with $\mathrm{CH}_{2} \mathrm{Cl}_{2}(35 \mathrm{~mL})$ and the combined organic layers were washed with deionized water $(30 \mathrm{~mL})$, dried over $\mathrm{Na}_{2} \mathrm{SO}_{4}$, filtered and evaporated under reduced pressure. The crude product was chromatographed over silica gel $\left(\mathrm{CH}_{2} \mathrm{Cl}_{2} / \mathrm{AcOEt}\right.$ 95/5), affording Boc-Val-Asp(TMSE)-OBn as a colorless oil (1.15 g, quantitative yield).

${ }^{1} \mathrm{H}$ NMR $\left(300 \mathrm{MHz}, \mathrm{CDCl}_{3}\right): \delta 0.02\left(\mathrm{~s}, 9 \mathrm{H}, \mathrm{Si}\left(\mathrm{CH}_{3}\right)_{3}\right), 0.83-0.93\left(\mathrm{~m}, 8 \mathrm{H}, \mathrm{CH}_{2} \mathrm{Si}+2 \mathrm{CH}_{3 \mathrm{Val}}\right)$, $1.43\left(\mathrm{~s}, 9 \mathrm{H}, \mathrm{C}\left(\mathrm{CH}_{3}\right)_{3}\right), 2.03-2.10\left(\mathrm{~m}, 1 \mathrm{H}, \mathrm{CHCH}_{3}\right), 2.78\left(\mathrm{dd}, J=4.5 \mathrm{~Hz}, J=17.0 \mathrm{~Hz}, 1 \mathrm{H}, \mathrm{CH}_{2}\right)$, $3.05\left(\mathrm{dd}, J=4.5 \mathrm{~Hz}, J=17.0 \mathrm{~Hz}, 1 \mathrm{H}, \mathrm{CH}_{2}\right), 3.94-3.98\left(\mathrm{~m}, 1 \mathrm{H}, \mathrm{C}^{*} H_{\text {Val }}\right), 4.11(\mathrm{t}, J=9.0 \mathrm{~Hz}, 2 \mathrm{H}$, $\left.\mathrm{OCH}_{2}\right), 4.86-4.90\left(\mathrm{~m}, 1 \mathrm{H}, \mathrm{C}^{*} H_{\text {Asp }}\right), 5.09-5.21\left(\mathrm{~m}, 3 \mathrm{H}, \mathrm{OCH}_{2} \mathrm{Ar}+\mathrm{N} H_{\text {Val }}\right), 6.82(\mathrm{~d}, J=8.0 \mathrm{~Hz}$, $\left.1 \mathrm{H}, \mathrm{NH}_{A s p}\right), 7.29(\mathrm{~s}, 5 \mathrm{H}, \mathrm{ArH}) ;{ }^{13} \mathrm{C} \mathrm{NMR}\left(75.4 \mathrm{MHz}, \mathrm{CDCl}_{3}\right): \delta-1.2(3 \mathrm{C}), 17.6,17.8,19.4$, 28.6 (3C), 31.7, 36.6, 48.7, 59.9, 63.9, 67.9, 80.1, 128.7-128.9 (2 peaks, 5C), 135.4, 156.0, 170.7, 171.5, 171.6; $\mathrm{R}_{f} 0.5\left(\mathrm{CH}_{2} \mathrm{Cl}_{2} / \mathrm{AcOEt} 96 / 4\right)$; IR (neat) 3324, 2960, 2900, 1732, 1661, $1505 \mathrm{~cm}^{-1} ;[\alpha]^{21}{ }_{365}+27.1^{\circ}\left(c 0.99, \mathrm{CHCl}_{3}\right)$; MS (MALDI-TOF, positive mode, CHCA matrix): calcd for $\left[\mathrm{C}_{26} \mathrm{H}_{42} \mathrm{~N}_{2} \mathrm{O}_{7} \mathrm{SiNa}\right]^{+}$545.27, found 545.63; Anal. Calcd for $14 \mathrm{C}_{26} \mathrm{H}_{42} \mathrm{~N}_{2} \mathrm{O}_{7} \mathrm{Si}_{\text {. }} \mathrm{CHCl}_{2}$ : C, 59.22; H, 8.03; N, 5.30. Found: C, 59.24; H, 8.07; N, 5.31.

\section{H-Val-Asp(TMSE)-Bn (TFA salt):}
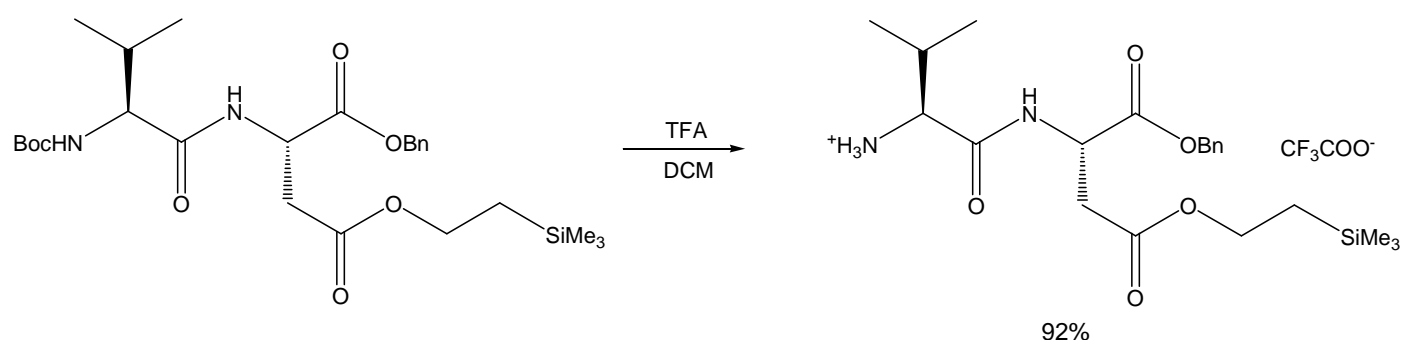

Boc-Val-Asp(TMSE)-OBn (1.03 g, $1.98 \mathrm{mmol})$ was dissolved in dry $\mathrm{CH}_{2} \mathrm{Cl}_{2}(24 \mathrm{~mL})$. The solution was cooled to $0^{\circ} \mathrm{C}$ and TFA ( $3 \mathrm{~mL}, 40 \mathrm{mmol}, 20$ eq.) was added. The reaction mixture was stirred at room temperature for $90 \mathrm{~min}$. Then, the mixture was cooled to $0^{\circ} \mathrm{C}$ and a solution of sat. $\mathrm{NaHCO}_{3}(50 \mathrm{~mL})$ was added. The aqueous layer was extracted twice with $\mathrm{CH}_{2} \mathrm{Cl}_{2}(25$ $\mathrm{mL})$ and the combined organic phases were washed with deionized water $(30 \mathrm{~mL})$, dried over $\mathrm{Na}_{2} \mathrm{SO}_{4}$ and filtered. TFA $(175 \mu \mathrm{L}, 2.38 \mathrm{mmol}, 1.2$ eq.) was added and the organic layer was concentrated under reduced pressure, affording the TFA salt of H-Val-Asp(TMSE)-OBn as a white solid (977 mg, 92\%).

${ }^{1} \mathrm{H}$ NMR $\left(300 \mathrm{MHz}, \mathrm{CDCl}_{3}\right): \delta 0.01\left(\mathrm{~s}, 9 \mathrm{H}, \mathrm{Si}\left(\mathrm{CH}_{3}\right)_{3}\right), 0.88-0.99\left(\mathrm{~m}, 8 \mathrm{H}, \mathrm{CH}_{2} \mathrm{Si}+2 \mathrm{CH}_{3 \mathrm{Val}}\right)$, 2.13-2.19 (m, $\left.1 \mathrm{H}, \mathrm{CHCH}_{3}\right), 2.76\left(\mathrm{dd}, J=5.0 \mathrm{~Hz}, J=17.0 \mathrm{~Hz}, 1 \mathrm{H}, \mathrm{CH}_{2}\right), 2.98(\mathrm{dd}, J=5.0 \mathrm{~Hz}, \mathrm{~J}$ 
$\left.=17.0 \mathrm{~Hz}, 1 \mathrm{H}, \mathrm{CH}_{2}\right), 3.85\left(\mathrm{~d}, J=5.0 \mathrm{~Hz}, 1 \mathrm{H}, \mathrm{C}^{*} H_{V a l}\right), 4.05-4.13\left(\mathrm{~m}, 2 \mathrm{H}, \mathrm{OCH}_{2}\right), 4.91-4.94(\mathrm{~m}$, $\left.1 \mathrm{H}, \mathrm{C}^{*} H_{A s p}\right), 5.13\left(\mathrm{dd}, J=11.0 \mathrm{~Hz}, J=12.0 \mathrm{~Hz}, 2 \mathrm{H}, \mathrm{OCH} H_{2} \mathrm{Ar}\right), 7.27-7.31(\mathrm{~m}, 5 \mathrm{H}, \mathrm{Ar} H) ; 7.55$ $\left(\mathrm{d}, J=8.0 \mathrm{~Hz}, 1 \mathrm{H}, \mathrm{N} H_{A s p}\right), 8.0-8.3\left(\mathrm{~m}_{\text {broad }}, 3 \mathrm{H}, \mathrm{NH}_{3}{ }^{+}\right) ;{ }^{13} \mathrm{C} \mathrm{NMR}\left(75.4 \mathrm{MHz}, \mathrm{CDCl}_{3}\right): \delta-1.3$ (3C), 17.4, 17.8, 18.0, 30.6, 35.9, 49.1, 59.0, 64.0, 68.1, 128.8-128.9 (2 peaks, 5C), 135.3, 168.3, 170.3, 171.7; IR (KBr): 3366, 2947, 1671, $1542 \mathrm{~cm}^{-1} ;[\alpha]^{21}{ }_{365}+38.7^{\circ}\left(c 0.97, \mathrm{CHCl}_{3}\right)$; MS (ESI, positive mode): calcd for $\left[\mathrm{C}_{21} \mathrm{H}_{35} \mathrm{~N}_{2} \mathrm{O}_{5} \mathrm{Si}\right]^{+} 423.23$, found 423.13; Anal Calcd for $\mathrm{C}_{23} \mathrm{H}_{35} \mathrm{~F}_{3} \mathrm{~N}_{2} \mathrm{O}_{7} \mathrm{Si}$ : C, 51.48; H, 6.57; N, 5.22. Found: C, 51.51; H, 6.43; N, 5.17.

\section{Ac-Asp(TMSE)-Glu(TMSE)-Val-Asp(TMSE)-OBn:}
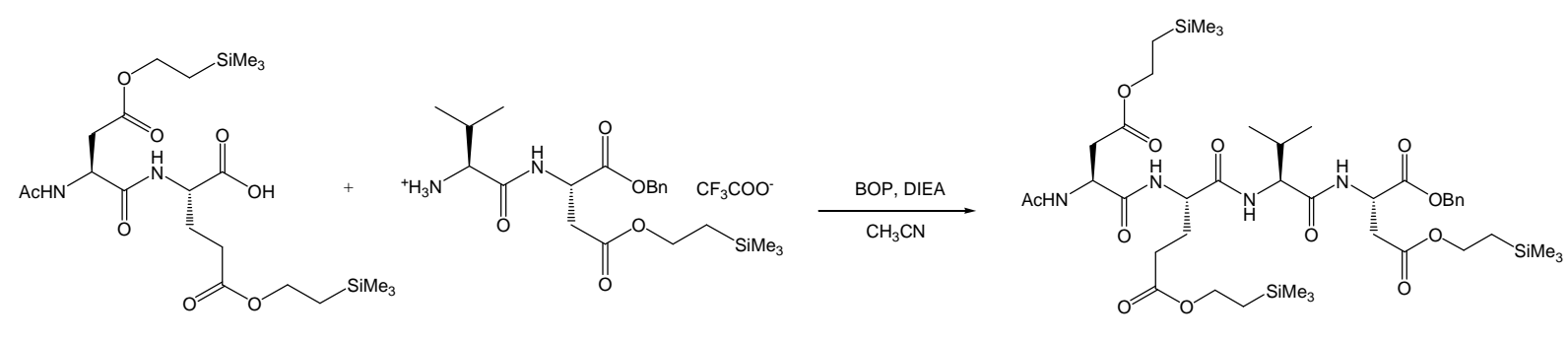

Ac-Asp(TMSE)-Glu(TMSE)-OH (175 mg, $0.35 \mathrm{mmol})$ and TFA.H-Val-Asp(TMSE)-OBn (187 mg, $0.35 \mathrm{mmol}, 1$ eq.) were dissolved in dry $\mathrm{CH}_{3} \mathrm{CN}$ (4 mL). Then, BOP reagent (155 mg, $0.35 \mathrm{mmol}, 1$ eq.) and DIEA (183 $\mu \mathrm{L}, 1.05 \mathrm{mmol}, 3$ eq.) were added and the resulting reaction mixture was stirred at room temperature for $1 \mathrm{~h}$. The solvent was removed under vacuum, the resulting solid was dissolved in $\mathrm{CH}_{2} \mathrm{Cl}_{2}(15 \mathrm{~mL})$ and washed with a sat. solution of $\mathrm{NaHCO}_{3}(7$ $\mathrm{mL})$. The aqueous layer was extracted twice with $\mathrm{CH}_{2} \mathrm{Cl}_{2}(10 \mathrm{~mL})$ and the combined organic layers were washed with deionized water $(12 \mathrm{~mL})$, dried over $\mathrm{Na}_{2} \mathrm{SO}_{4}$, filtered and evaporated under reduced pressure. The crude product was chromatographed over silica gel $\left(\mathrm{CH}_{2} \mathrm{Cl}_{2} / \mathrm{AcOEt} 1 / 1\right)$, affording Ac-Asp(TMSE)-Glu(TMSE)-Val-Asp(TMSE)-OBn as a beige solid (304 mg, 96\%).

${ }^{1} \mathrm{H}$ NMR $\left(300 \mathrm{MHz}, \mathrm{CDCl}_{3}\right): \delta 0.01\left(\mathrm{~s}, 9 \mathrm{H}, \mathrm{Si}\left(\mathrm{CH}_{3}\right)_{3}\right), 0.02\left(\mathrm{~s}, 9 \mathrm{H}, \mathrm{Si}\left(\mathrm{CH}_{3}\right)_{3}\right), 0.03$ (s, 9H, $\left.\mathrm{Si}\left(\mathrm{CH}_{3}\right)_{3}\right), 0.82-1.01\left(\mathrm{~m}, 12 \mathrm{H}, 3 \mathrm{CH}_{2} \mathrm{Si}+2 \mathrm{CH}_{3 \mathrm{Val}}\right), 2.05-2.22\left(\mathrm{~m}, 6 \mathrm{H}, \mathrm{CHCH}_{3}+\mathrm{CH}_{2 \mathrm{Glu}}+\mathrm{CH}_{3}\right)$, 2.42-2.49 (m, $\left.2 \mathrm{H}, \mathrm{CH}_{2} \mathrm{CO}_{\mathrm{Glu}}\right), 2.70-3.15\left(\mathrm{~m}, 4 \mathrm{H}, 2 \mathrm{CH}_{2 \mathrm{Asp}}\right), 4.02-4.19\left(\mathrm{~m}, 6 \mathrm{H}, \mathrm{OCH}_{2}\right), 4.27-4.38$ $\left(\mathrm{m}, 2 \mathrm{H}, \mathrm{C}^{*} H_{V a l}+\mathrm{C}^{*} H_{G l u}\right), 4.72-4.76\left(\mathrm{~m}, 1 \mathrm{H}, \mathrm{C}^{*} H_{\text {Asp }}\right), 4.87-4.95\left(\mathrm{~m}, 1 \mathrm{H}, \mathrm{C}^{*} H_{\text {Asp }}\right), 5.15(\mathrm{dd}, J=$ $\left.12.0 \mathrm{~Hz}, J=19.0 \mathrm{~Hz}, 2 \mathrm{H}, \mathrm{OCH}_{2} \mathrm{Ar}\right), 6.91\left(\mathrm{~d}, J=8.0 \mathrm{~Hz}, 1 \mathrm{H}, \mathrm{N} H_{A s p}\right), 7.07(\mathrm{~d}, J=8.0 \mathrm{~Hz}, 1 \mathrm{H}$, $\left.\mathrm{N} H_{A s p}\right), 7.12\left(\mathrm{~d}, J=8.0 \mathrm{~Hz}, 1 \mathrm{H}, \mathrm{N} H_{V a l}\right), 7.32(\mathrm{~s}, 5 \mathrm{H}, \mathrm{ArH}), 7.79\left(\mathrm{~d}, J=8.0 \mathrm{~Hz}, 1 \mathrm{H}, \mathrm{N} H_{G l u}\right) ;{ }^{13} \mathrm{C}$ NMR (75.4 MHz, $\mathrm{CDCl}_{3}$ ): $\delta$-1.2 (9C), 17.5-17.6 (2 peaks, 3C), 18.0, 19.5, 23.4, 26.6, 30.7, 31.1, 36.2, 36.6, 49.0, 49.9, 54.5, 58.9, 63.7, 63.9, 64.0, 67.9, 128.7-128.9 (3 peaks, 5C), 135.5, 170.9, 171.0, 171.1, 171.3, 171.4, 171.7, 172.5, 175.0; IR (KBr): 3276, 2955, 1737, $1634 \mathrm{~cm}^{-1}$; $[\alpha]^{21}{ }_{365}-36.4^{\circ}\left(c 0.95, \mathrm{CHCl}_{3}\right) ; \mathrm{R}_{f} 0.5\left(\mathrm{CH}_{2} \mathrm{Cl}_{2} / \mathrm{AcOEt} 1 / 1\right)$; MS (MALDI-TOF, positive mode, CHCA matrix): calcd for $\left[\mathrm{C}_{42} \mathrm{H}_{72} \mathrm{~N}_{4} \mathrm{O}_{12} \mathrm{Si}_{3} \mathrm{Na}\right]^{+}$931.43, found 931.57; Anal Calcd for $\mathrm{C}_{42} \mathrm{H}_{72} \mathrm{~N}_{4} \mathrm{O}_{12} \mathrm{Si}_{3}, 0.6 \mathrm{CH}_{2} \mathrm{Cl}_{2}$ : C, 53.28; $\mathrm{H}, 7.68 ; \mathrm{N}$, 5.83. Found: C, 53.36; H, 7.40; N, 5.89. 

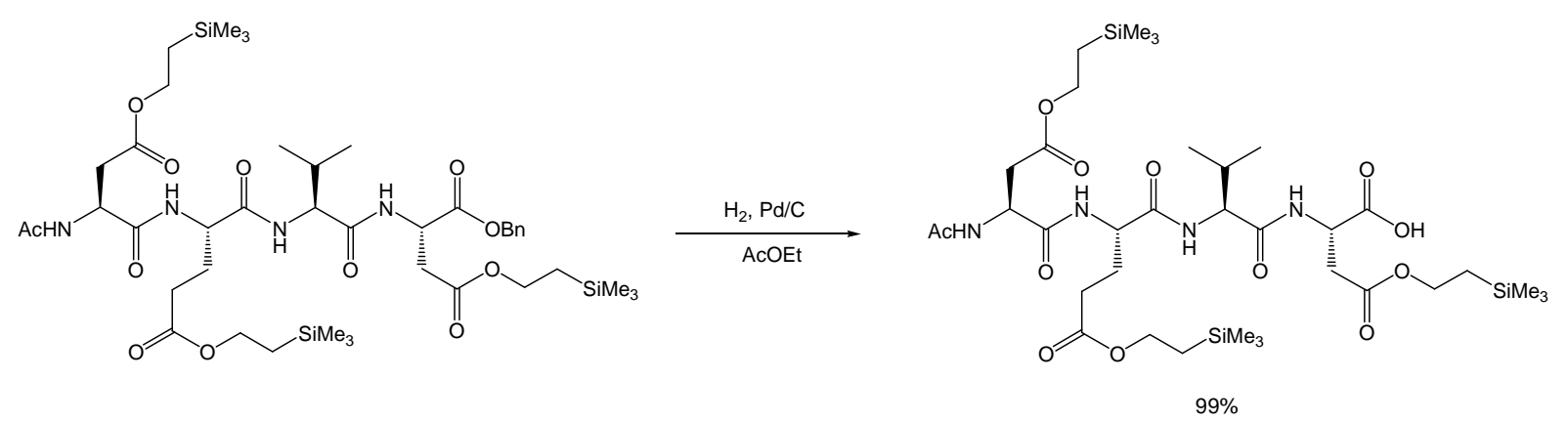

Ac-Asp(TMSE)-Glu(TMSE)-Val-Asp(TMSE)-OBn (1.88 g, $2.07 \mathrm{mmol})$ was dissolved in AcOEt $(40 \mathrm{~mL})$. The solution was cooled to $0^{\circ} \mathrm{C}$ and $\mathrm{Pd} / \mathrm{C}$ catalyst $(10 \%, 120 \mathrm{mg})$ was added. Then, the reaction mixture was put under an hydrogen atmosphere and stirred at room temperature overnight. The $\mathrm{Pd} / \mathrm{C}$ catalyst was removed by filtration through a Celite ${ }^{\circledR} 545 \mathrm{pad}$, washed with $\mathrm{MeOH}$ and the filtrate was concentrated under vacuum, yielding Ac-Asp(TMSE)Glu(TMSE)-Val-Asp(TMSE)-OH 7 as a gray solid (1.69 g, quantitative yield).

${ }^{1} \mathrm{H}$ NMR $\left(300 \mathrm{MHz}, \mathrm{CD}_{3} \mathrm{OD}\right): \delta 0.08\left(\mathrm{~s}, 27 \mathrm{H}, 3 \mathrm{Si}\left(\mathrm{CH}_{3}\right)_{3}\right), 0.96-1.08\left(\mathrm{~m}, 12 \mathrm{H}, 3 \mathrm{CH}_{2} \mathrm{Si}+\right.$ 2 $\left.\mathrm{CH}_{3 \text { Val }}\right), 1.91-2.05\left(\mathrm{~m}, 4 \mathrm{H}, \mathrm{CH}_{2 \mathrm{Glu}}+\mathrm{CH}_{3}\right), 2.12-2.24\left(\mathrm{~m}, 2 \mathrm{H}, \mathrm{CHCH}_{3}+\mathrm{CH}_{2 \mathrm{Glu}}\right), 2.38-2.50$ (m, $\left.2 \mathrm{H}, \mathrm{CH}_{2} \mathrm{CO}_{\mathrm{Glu}}\right), 2.65-2.93\left(\mathrm{~m}, 4 \mathrm{H}, 2 \mathrm{CH}_{2 A s p}\right), 4.16-4.28\left(\mathrm{~m}, 7 \mathrm{H}, \mathrm{C}^{*} \mathrm{H}_{\text {Val }}+\mathrm{OCH}_{2}\right), 4.40-4.45(\mathrm{~m}$, $\left.1 \mathrm{H}, \mathrm{C}^{*} H_{G l u}\right), 4.70-4.80\left(\mathrm{~m}, 2 \mathrm{H}, \mathrm{C}^{*} H_{A s p}\right), 7.97\left(\mathrm{~d}, J=8.0 \mathrm{~Hz}, 1 \mathrm{H}, \mathrm{N} H_{\text {Val }}\right), 8.22(\mathrm{~d}, J=8.0 \mathrm{~Hz}$, $\left.1 \mathrm{H}, \mathrm{N} H_{A s p}\right), 8.32\left(\mathrm{~d}, J=8.0 \mathrm{~Hz}, 1 \mathrm{H}, \mathrm{N} H_{A s p}\right), 8.41\left(\mathrm{~d}, J=8.0 \mathrm{~Hz}, 1 \mathrm{H} \mathrm{N} H_{G l u}\right) ;{ }^{13} \mathrm{C}$ NMR $(75.4$ $\left.\mathrm{MHz}, \mathrm{CD}_{3} \mathrm{OD}\right): \delta$ - 0.6 (9C), 19.0 (3C), 19.6, 20.6, 23.4, 28.8, 32.3, 32.6, 37.8, 38.1, 51.2, 52.2, $55.0,61.0,64.7,65.0,65.2,173.1,173.3,173.8,173.9,174.0,174.2(0), 174.2(4), 175.7$; IR (KBr): $3926,2958,1732,1694,1668,1645,1564,1538 \mathrm{~cm}^{-1} ;[\alpha]^{21}{ }_{365}+17.5^{\circ}\left(c 0.94, \mathrm{CHCl}_{3}\right)$; $\mathrm{R}_{f} 0.5\left(\mathrm{CH}_{2} \mathrm{Cl}_{2} / \mathrm{MeOH} 95 / 5\right)$; MS (MALDI-TOF, positive mode, CHCA matrix): calcd for $\left[\mathrm{C}_{35} \mathrm{H}_{66} \mathrm{~N}_{4} \mathrm{O}_{12} \mathrm{Si}_{3} \mathrm{Na}\right]^{+}$841.39, found 841.57; Anal Calcd for $\mathrm{C}_{35} \mathrm{H}_{66} \mathrm{~N}_{4} \mathrm{O}_{12} \mathrm{Si}_{3}, 1.2 \mathrm{CH}_{2} \mathrm{Cl}_{2}$ : $\mathrm{C}$, 47.20; H, 7.48; N, 6.08. Found: C, 47.14; H, 7.22; N, 6.21.

\section{Ac-DEVD(TMSE)-PABA-OH 9:}
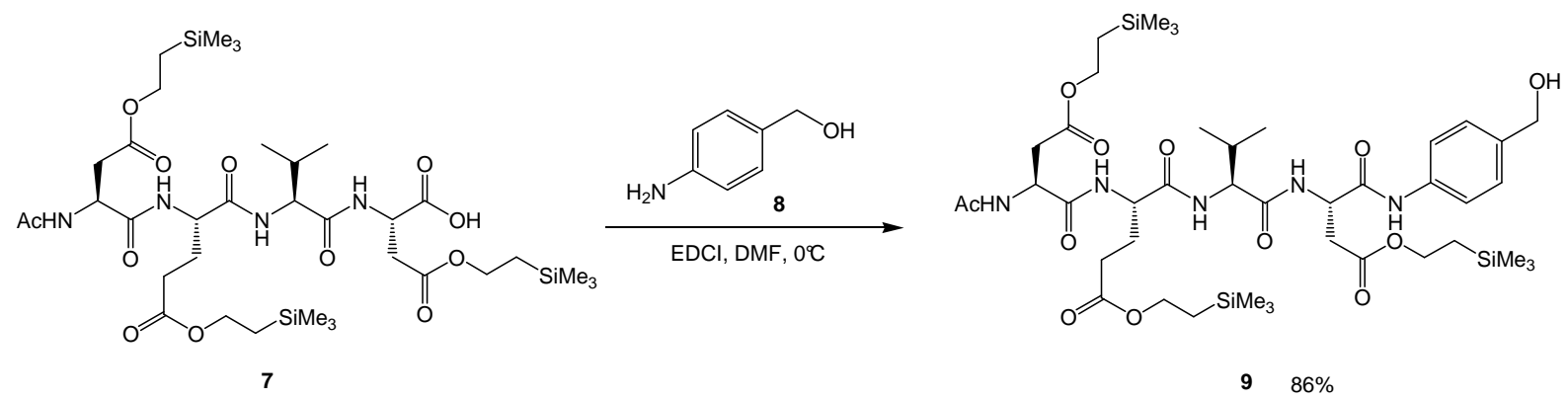

Ac-DEVD(TMSE)-OH 7 (598 mg, $0.73 \mathrm{mmol}$ ) was dissolved in dry DMF (7 mL) and cooled to $0^{\circ} \mathrm{C}$. Then, $p$-aminobenzyl alcohol 8 (PABA) $\left(90 \mathrm{mg}, 0.73 \mathrm{mmol}, 1\right.$ eq.) and $N$-Ethyl- $N^{\prime}-(3-$ dimethylaminopropyl)carbodiimide hydrochloride (EDC) $(154 \mathrm{mg}, 0.80 \mathrm{mmol}, 1.1 \mathrm{eq}$.) were sequentially added and the resulting reaction mixture was stirred at room temperature for $1 \mathrm{~h}$. The solvent was removed under vacuum, the resulting solid was dissolved in $\mathrm{CH}_{2} \mathrm{Cl}_{2}(40 \mathrm{~mL})$, washed with aq. citric acid $(10 \%)(15 \mathrm{~mL})$ and deionized water $(20 \mathrm{~mL})$. The organic layer was dried over $\mathrm{Na}_{2} \mathrm{SO}_{4}$, filtered and concentrated under reduced pressure. The crude product was 
purified on silica gel $\left(\mathrm{CH}_{2} \mathrm{Cl}_{2} / \mathrm{AcOEt} 3 / 7\right)$, yielding Ac-DEVD-PABA-OH 9 as a mixture (9/1) of two diastereomers which were resolved in the next step (yellow solid, $580 \mathrm{mg}, 86 \%$ ). For analytical purpose, the mixture was purified by semi-preparative RP-HPLC (system C).

${ }^{1} \mathrm{H}$ NMR $\left(300 \mathrm{MHz}, \mathrm{CD}_{3} \mathrm{OD}\right): \delta 0.07\left(\mathrm{~s}, 27 \mathrm{H}, 3 \mathrm{Si}\left(\mathrm{CH}_{3}\right)_{3}\right), 0.99-1.04\left(\mathrm{~m}, 12 \mathrm{H}, 3 \mathrm{CH}_{2} \mathrm{Si}+\right.$ $2 \mathrm{CH}_{3 \text { Val }}$ ), 1.95-2.10 (m, 4H, $\left.\mathrm{CH}_{2 G l u}+\mathrm{CH}_{3}\right), 2.10-2.18\left(\mathrm{~m}, 2 \mathrm{H}, \mathrm{CHCH}_{3}+\mathrm{CH}_{2 G l u}\right), 2.41-2.48(\mathrm{~m}$, $\left.2 \mathrm{H}, \mathrm{CH}_{2} \mathrm{CO}_{\text {Glu }}\right), 2.7-3.1\left(\mathrm{~m}, 4 \mathrm{H}, 2 \mathrm{CH}_{2 \mathrm{Asp}}\right), 4.05-4.25\left(\mathrm{~m}, 7 \mathrm{H}, \mathrm{C}^{*} \mathrm{H}_{\text {Val }}+3 \mathrm{OCH}_{2}\right), 4.36-4.42(\mathrm{~m}$, $\left.1 \mathrm{H}, \mathrm{C}^{*} H_{G l u}\right), 4.58\left(\mathrm{~s}, 2 \mathrm{H}, \mathrm{ArCH}_{2} \mathrm{O}\right), 4.70-4.76\left(\mathrm{~m}, 1 \mathrm{H}, \mathrm{C}^{*} H_{A s p}\right), 4.80-4.95\left(\mathrm{~m}, 1 \mathrm{H}, \mathrm{C}^{*} H_{A s p}\right), 7.33$ $(\mathrm{d}, J=8.0 \mathrm{~Hz}, 2 \mathrm{H}, \operatorname{Ar} H), 7.63(\mathrm{~d}, J=8.0 \mathrm{~Hz}, 2 \mathrm{H}, \operatorname{Ar} H), 7.94\left(\mathrm{~d}, J=7.0 \mathrm{~Hz}, 1 \mathrm{H}, \mathrm{N} H_{\text {Val }}\right), 8.31$ $\left(\mathrm{d}, J=8.0 \mathrm{~Hz}, 1 \mathrm{H}, \mathrm{N} H_{A s p}\right), 8.42-8.47\left(\mathrm{~m}, 2 \mathrm{H}, \mathrm{N} H_{G l u}+\mathrm{N} H_{A s p}\right), 9.48(\mathrm{~s}, 1 \mathrm{H}, \mathrm{OH}) ;{ }^{13} \mathrm{C} \mathrm{NMR}$ (75.4 MHz, $\mathrm{CD}_{3} \mathrm{OD}$ ): $\delta-0.6,19.1,20.0,20.5,23.4,28.4,32.1,32.3,37.7,52.3,53.1,55.7$, 62.2, 64.8, 65.1, 65.3, 65.7, 122.2, 129.4, 139.3, 139.7, 171.4, 173.0, 173.4, 174.2(6), 174.3(4), 174.4, 175.2, 175.7; IR (KBr): 3286, 2957, 1738, 1634, 1539, 1251, 1172, $\mathrm{cm}^{-1} ;[\alpha]^{21}{ }_{365}-125.5^{\circ}$ (c 1.1, $\left.\mathrm{CHCl}_{3}\right) ; \mathrm{R}_{f} 0.5\left(\mathrm{CH}_{2} \mathrm{Cl}_{2} / \mathrm{AcOEt} 3 / 7\right) ; \mathrm{MS}$ (ESI, positive mode): calcd for $\left[\mathrm{C}_{42} \mathrm{H}_{73} \mathrm{~N}_{5} \mathrm{O}_{13} \mathrm{Si}_{3} \mathrm{Na}\right]^{+}$946.40, found 946.45 .

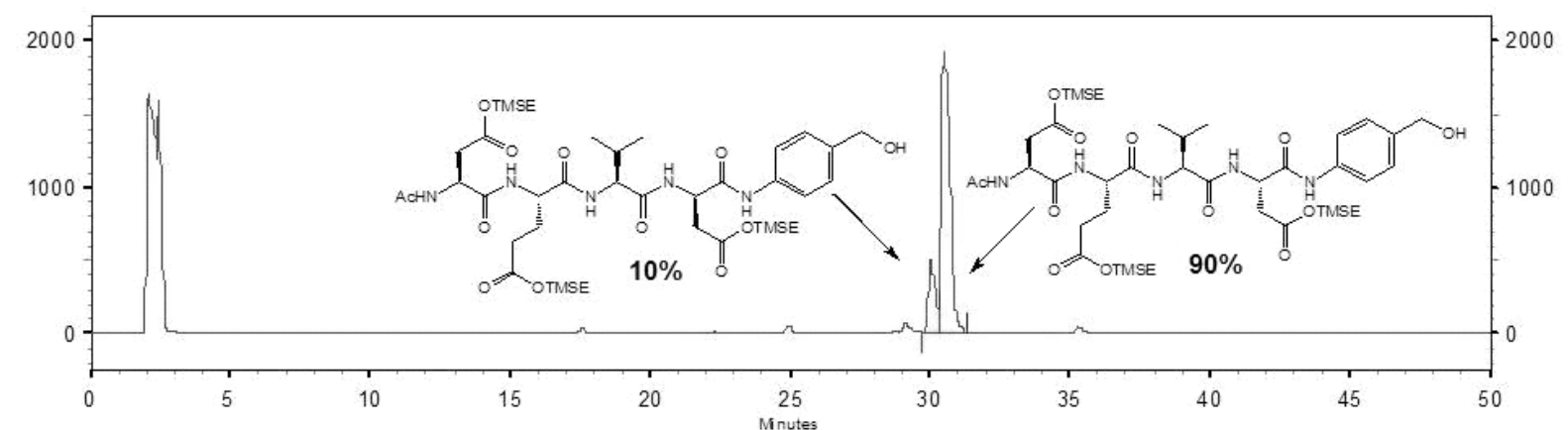

Figure S1. RP-HPLC (system A) elution profile of the crude reaction mixture of peptide coupling between 7 and 8. Two diastereomers could be detected in a $9 / 1$ ratio.

\section{Compound 11:}
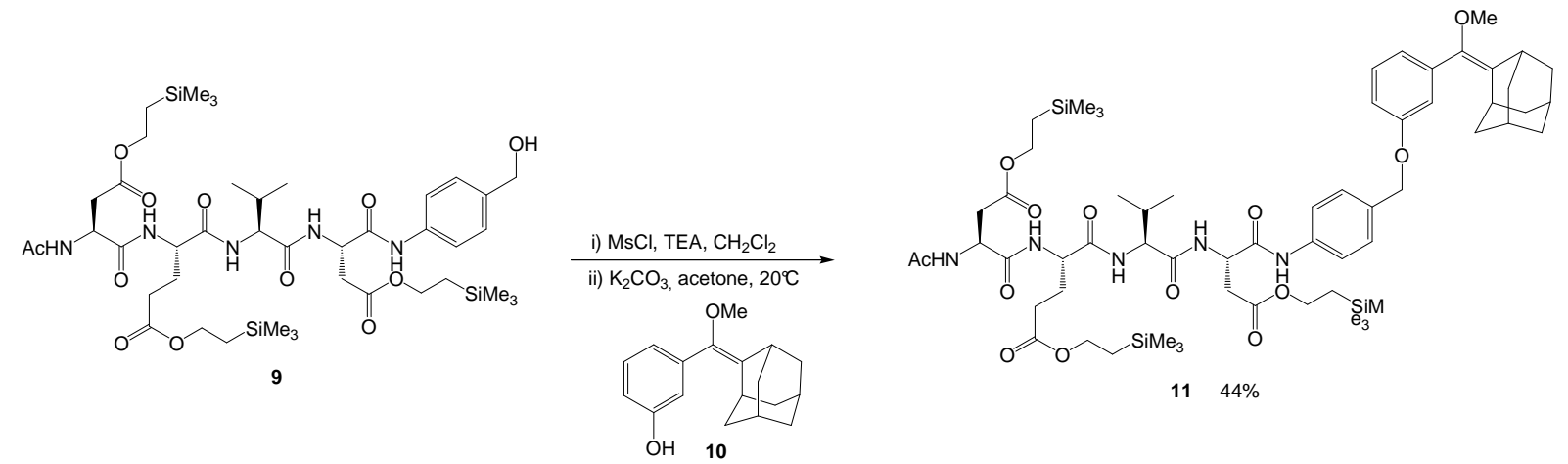

Benzyl alcohol 9 (165 mg, $0.17 \mathrm{mmol})$ was dissolved in a mixture of dry acetone $(500 \mu \mathrm{L})$ and $\mathrm{CH}_{2} \mathrm{Cl}_{2}(3 \mathrm{~mL})$. The solution was cooled to $0^{\circ} \mathrm{C}$, triethylamine $(118 \mu \mathrm{L}, 0.85 \mathrm{mmol}, 5$ eq. $)$ and methanesulfonyl chloride ( $66 \mu \mathrm{L}, 0.85 \mathrm{mmol}, 5$ eq.) were sequentially added and the resulting reaction mixture was stirred overnight. The medium was diluted with $\mathrm{CH}_{2} \mathrm{Cl}_{2}(5 \mathrm{~mL})$ and pourred into cold aq. $\mathrm{HCl}(2 \mathrm{~N})$. The aqueous layer was extracted with $\mathrm{CH}_{2} \mathrm{Cl}_{2}(10 \mathrm{~mL})$. The combined organic layers were washed with deionized water $(8 \mathrm{~mL})$, dried over $\mathrm{Na}_{2} \mathrm{SO}_{4}$, filtered and evaporated under reduced pressure, affording the mesylated compound as a yellow solid. The crude product was used without purification in the next step.

Enol ether 10 (46 mg, $0.17 \mathrm{mmol}, 1$ eq. based on the former step) was dissolved in dry acetone (1 mL). $\mathrm{K}_{2} \mathrm{CO}_{3}$ (47 mg, $0.34 \mathrm{mmol}, 2$ eq.) was added and the mixture was stirred for $20 \mathrm{~min}$. Then, mesylate in solution in dry acetone $(1.5 \mathrm{~mL})$ was added and the mixture was stirred at 
room temperature overnight. The reaction was checked to completion by TLC and the reaction mixture was diluted with $\mathrm{CH}_{2} \mathrm{Cl}_{2}(15 \mathrm{~mL})$ and washed with deionized water $(7 \mathrm{~mL})$. The organic layer was dried over $\mathrm{Na}_{2} \mathrm{SO}_{4}$, filtered and evaporated under reduced pressure. The crude product was purified by chromatography over silica gel, affording $\mathbf{1 1}$ as pale yellow oil (88 mg, 44\%).

${ }^{1} \mathrm{H}$ NMR $\left(300 \mathrm{MHz}, \mathrm{CDCl}_{3}\right): \delta 0.02\left(\mathrm{~s}, 9 \mathrm{H}, \mathrm{Si}\left(\mathrm{CH}_{3}\right)_{3}\right), 0.04\left(\mathrm{~s}, 9 \mathrm{H}, \mathrm{Si}\left(\mathrm{CH}_{3}\right)_{3}\right), 0.06(\mathrm{~s}, 9 \mathrm{H}$, $\left.\mathrm{Si}\left(\mathrm{CH}_{3}\right)_{3}\right)$, 0.92-0.98 (m, $\left.12 \mathrm{H}, 3 \mathrm{CH}_{2} \mathrm{Si}+2 \mathrm{CH}_{3 \text { Val }}\right), 1.77-1.94\left(\mathrm{~m}, 15 \mathrm{H}, \mathrm{CH}_{\text {Adam. }}+\mathrm{CH}_{2 \text { Adam. }}+\right.$ $\left.\mathrm{CH}_{3}\right), 2.31-2.42\left(\mathrm{~m}, 3 \mathrm{H}, \mathrm{CHCH}_{3}+\mathrm{CH}_{2 \mathrm{Glu}}\right), 2.50-2.63\left(\mathrm{~m}, 3 \mathrm{H}, \mathrm{CH}_{\text {Adam. }}+\mathrm{CH}_{2} \mathrm{CO}_{\text {Glu }}\right), 2.83-2.95$ $\left(\mathrm{m}, 4 \mathrm{H}, 2 \mathrm{CH}_{2 A s p}\right), 3.22\left(\mathrm{~s}, 1 \mathrm{H}, \mathrm{CH}_{\text {Adam. }}\right), 3.27$ (s, 3H, OCH 3 ), 3.84-3.89 (m, $\left.1 \mathrm{H}, \mathrm{C}^{*} H_{\text {Asp }}\right), 4.05-$ $4.20\left(\mathrm{~m}, 7 \mathrm{H}, \mathrm{C}^{*} H_{\text {Val }}+3 \mathrm{OCH}_{2}\right), 4.69-4.75\left(\mathrm{~m}, 1 \mathrm{H}, \mathrm{C}^{*} H_{\text {Glu }}\right), 4.98\left(\mathrm{~s}_{\text {Broad }}, 3 \mathrm{H}, \mathrm{ArOCH}_{2}+\mathrm{C}^{*} H_{\text {Asp }}\right)$, 6.82-6.92 (m, 3H, ArH), $7.14\left(\mathrm{~d}, J=8.0 \mathrm{~Hz}, 1 \mathrm{H}, \mathrm{N} H_{G l u}\right), 7.19-7.25\left(\mathrm{~m}, 2 \mathrm{H}, \mathrm{N} H_{A s p}+\mathrm{ArH}\right), 7.37$ $\left(\mathrm{d}, J=9.0 \mathrm{~Hz}, 4 \mathrm{H}, \mathrm{Ar} H_{P A B A}+\mathrm{N} H_{A s p}+\mathrm{N} H_{V a l}\right), 7.68\left(\mathrm{~s}, 2 \mathrm{H}, \mathrm{Ar} H_{P A B A}\right), 8.62(\mathrm{~s}, 1 \mathrm{H}, \mathrm{N} H \mathrm{Ac}) ;{ }^{13} \mathrm{C}$ NMR (75.4 MHz, $\mathrm{CDCl}_{3}$ ): $\delta$-1.2 (9C), 17.6 (3C), 18.3, 19.5, 23.3, 26.7, 28.6 (2C), 29.8, 30.0, 30.5, 31.4, 32.5, 35.6, 36.0, 37.5, 39.4 (2C), 39.5 (2C), 49.8, 50.5, 54.1, 58.2, 63.4 (2C), 63.8, 70.0, 114.4, 115.8, 120.3 (2C), 122.5, 128.7 (2C), 129.2, 132.2, 133.1, 137.2, 138.1, 138.2, 143.6, 168.8, 170.2, 171.3, 171.7, 172.0, 173.3, 174.5, 175.8; IR (KBr): 3322, 2925, 1720, $1655,1536 \mathrm{~cm}^{-1} ;[\alpha]^{21}{ }_{365}-23.7^{\circ}\left(c 0.95, \mathrm{CHCl}_{3}\right) ; \mathrm{R}_{f} 0.5\left(\mathrm{CH}_{2} \mathrm{Cl}_{2} / \mathrm{AcOEt} 1 / 1\right)$; MS (ESI, positive mode): calcd for $\left[\mathrm{C}_{60} \mathrm{H}_{93} \mathrm{~N}_{5} \mathrm{O}_{13} \mathrm{Si}_{3} \mathrm{Na}\right]^{+} 1198.60$, found 1198.53; HPLC (system B) $: t_{\mathrm{R}}=39.6$ $\min$ (purity > 98\%).

\section{Dioxetane 11' precursor of compound 12:}

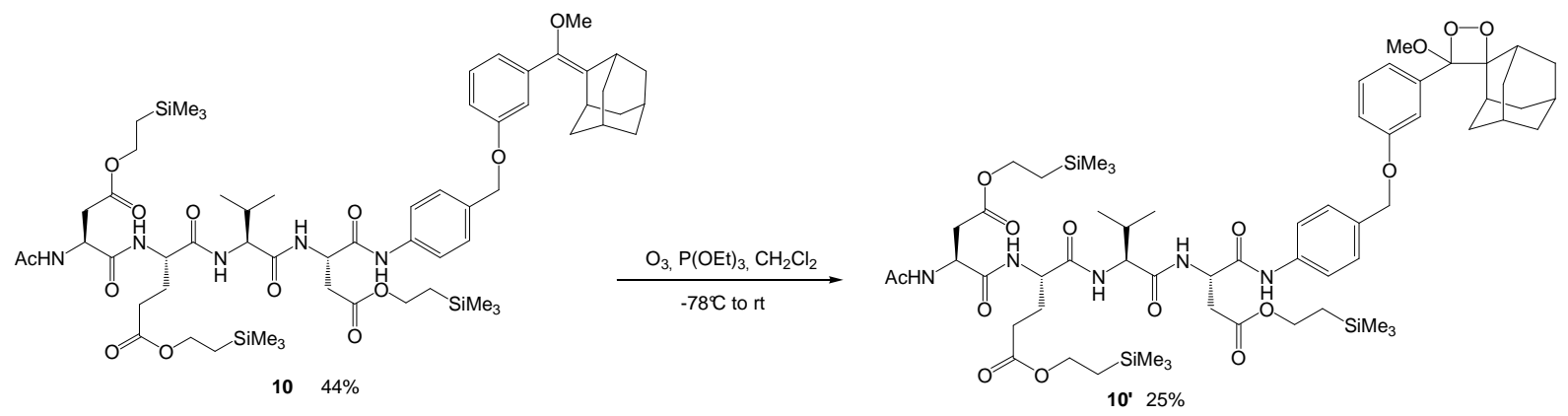

$\mathrm{P}(\mathrm{OEt})_{3}(22 \mu \mathrm{L}, 0.085 \mathrm{mmol}, 2.7$ eq.) was introduced in a 2-neck round bottom flask ( $25 \mathrm{~mL})$ containing $2 \mathrm{~mL}$ of dry $\mathrm{CH}_{2} \mathrm{Cl}_{2}$. The solution was cooled to $-78^{\circ} \mathrm{C}$ and ozone $\left(\mathrm{O}_{3}\right)$ was bubbled until a blue color (excess of $\mathrm{O}_{3}$ ) appeared. Then, the medium was purged with argon until the solution became colorless. Enol ether $11(37 \mathrm{mg}, 0.031 \mathrm{mmol})$ in solution in dry $\mathrm{CH}_{2} \mathrm{Cl}_{2}(2 \mathrm{~mL})$ was added and the resulting reaction mixture was allowed to warm at room temperature. After $1 \mathrm{~h}$, the formation of the dioxetane was checked by analytical RP-HPLC (system D): the RPHPLC elution profile showed $\sim 50 \%$ conversion of the starting material. The reaction mixture was concentrated under reduced pressure and the resulting solid was purified by semipreparative RP-HPLC (system E), allowing the isolation of the dioxetane 11' as a white solid (10 mg, 25\%).

${ }^{1} \mathrm{H}$ NMR $\left(300 \mathrm{MHz}, \mathrm{CDCl}_{3}\right): \delta 0.03\left(\mathrm{~s}, 27 \mathrm{H}, \mathrm{Si}\left(\mathrm{CH}_{3}\right)_{3}\right), 0.94-1.02\left(\mathrm{~m}, 12 \mathrm{H}, 3 \mathrm{CH}_{2} \mathrm{Si}+\right.$ $\left.2 \mathrm{CH}_{3 \mathrm{Val}}\right), 1.43-1.78\left(\mathrm{~m}, 12 \mathrm{H}, \mathrm{CH}_{\text {Adam }}+\mathrm{CH}_{2 \text { Adam }}\right), 1.98\left(\mathrm{~s}, 3 \mathrm{H}, \mathrm{CH}_{3}\right), 2.22-2.52\left(\mathrm{~m}, 6 \mathrm{H}, \mathrm{CHCH}_{3}\right.$ $\left.+\mathrm{CH}_{\text {Adam }}+\mathrm{CH}_{2} \mathrm{CO}_{\text {Glu }}+\mathrm{CH}_{2 G l u}\right), 2.78-3.02\left(\mathrm{~m}, 4 \mathrm{H}, 2 \mathrm{CH}_{2 A s p}\right), 3.20\left(\mathrm{~s}, 1 \mathrm{H}, \mathrm{CH}_{\text {Adam. }}\right), 3.21$ (s, $\left.3 \mathrm{H}, \mathrm{OCH}_{3}\right), 3.80-3.92\left(\mathrm{~m}, 1 \mathrm{H}, \mathrm{C}^{*} H_{A s p}\right), 4.08-4.22\left(\mathrm{~m}, 7 \mathrm{H}, \mathrm{C}^{*} H_{V a l}+3 \mathrm{OCH}_{2}\right), 4.75-4.82(\mathrm{~m}, 1 \mathrm{H}$, $\left.\mathrm{C}^{*} H_{G l u}\right), 5.05\left(\mathrm{~s}_{\text {Broad }}, 3 \mathrm{H}, \mathrm{ArOCH}_{2}+\mathrm{C}^{*} H_{\text {Asp }}\right), 6.36-6.40(\mathrm{~m}, 1 \mathrm{H}, \mathrm{ArH}), 6.99(\mathrm{~d}, J=6.0 \mathrm{~Hz}, 1 \mathrm{H}$,

\footnotetext{
${ }^{4}$ Stephenson, L. M.; Zielinski, M. B., J. Am. Chem. Soc. 1982, 104, 5819-5820; Greer, A., Acc. Chem. Res. 2006, 39, 797-804.
} 
$\operatorname{Ar} H), 7.30-7.38\left(\mathrm{~m}, 4 \mathrm{H}, 2 \operatorname{Ar} H_{P A B A}+2 \operatorname{Ar} H\right), 7.71\left(\mathrm{~d}, J=8.0 \mathrm{~Hz}, 2 \mathrm{H}, \operatorname{Ar} H_{P A B A}\right), 8.54-8.60(\mathrm{~m}$, 1H, NHAc); IR (KBr): 3310, 2917, 1719, 1655, 1542, 1389, 1250, $1165 \mathrm{~cm}^{-1}$; MS (ESI, positive mode): calcd for $\left[\mathrm{C}_{66} \mathrm{H}_{109} \mathrm{~N}_{6} \mathrm{O}_{15} \mathrm{Si}_{3}\right]^{+} 1309.73$, found 1309.53; HPLC (system $\left.\mathrm{B}\right): t_{\mathrm{R}}=$ 37.8 min (purity $>98 \%$ ).

\section{Dioxetane 12:}
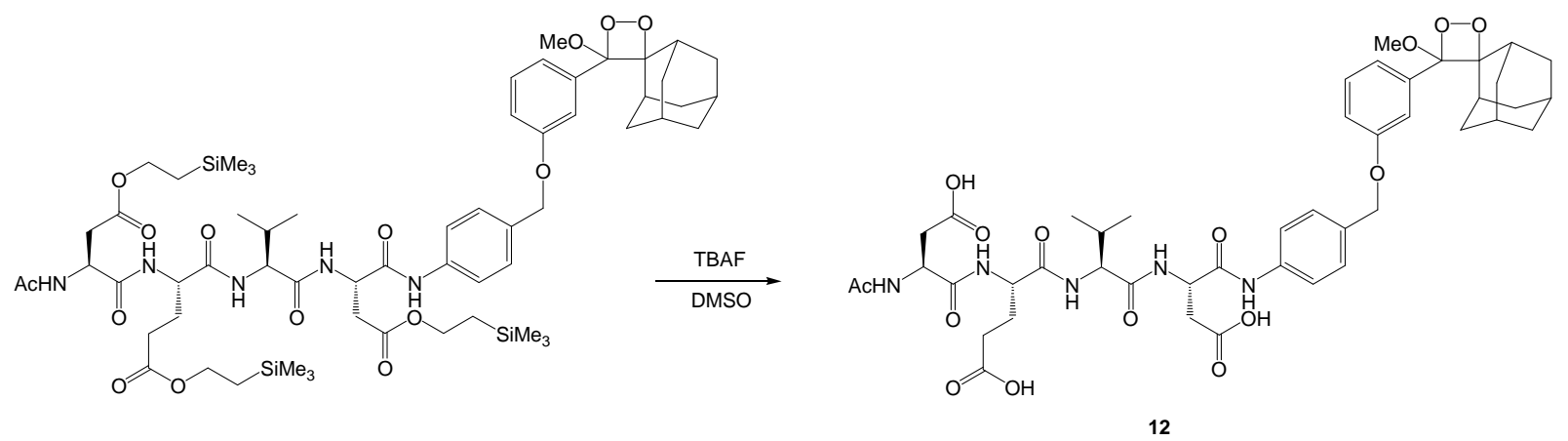

Dioxetane 11' $(2 \mathrm{mg}, 1.53 \mu \mathrm{mol})$ was dissolved in DMSO $(200 \mu \mathrm{L})$. TBAF (1M in THF, 31 $\mu \mathrm{L}, 31 \mu \mathrm{mol}, 20$ eq.) was added to the solution, allowing the quantitative removal of the TMSE groups (followed by RP-HPLC analysis after 5 min of reaction, system B). The mixture was diluted with TEAB buffer $(50 \mathrm{mM}, \mathrm{pH} 7.5)$ and purified by semi-preparative RP-HPLC (system F). The product-containing fractions were lyophilized to give the target dioxetane $\mathbf{1 2}$ as a colorless oil. Stock solution of this chemiluminescent probe was prepared in DMSO and UVvisible quantification was achieved in deionized water at $\lambda_{\max }=250 \mathrm{~nm}$ (yield after RP-HPLC purification: $50 \%)$.

HPLC (system B): $t_{\mathrm{R}}=27.1 \mathrm{~min}$, purity $>90 \%$. UV-visible (water, $25^{\circ} \mathrm{C}$ ): $\lambda_{\max }=250 \mathrm{~nm}, \varepsilon$ $(250 \mathrm{~nm})=19000 \mathrm{M}^{-1} \mathrm{~cm}^{-1}$; MS (ESI, negative mode): calcd for $\left[\mathrm{C}_{45} \mathrm{H}_{56} \mathrm{~N}_{5} \mathrm{O}_{15}\right]^{-}$906.38, found 906.33 . 


\section{Chemiluminescence in vitro assay}

\section{A. Detection of caspase-3:}

Dioxetane 12 was dissolved in caspase-3 buffer $(200 \mu \mathrm{L}, 10 \%$ (w/v) sucrose, $50 \mathrm{mM}$ PIPES, $100 \mathrm{mM}$ $\mathrm{NaCl}, 10 \mathrm{mM}$ DTT, $1 \mathrm{mM}$ EDTA, $0.1 \%$ (w/v) CHAPS, $\mathrm{pH} 7.4$ ). $1 \mu \mathrm{L}$ of recombinant human caspase-3 $\left(1.610^{-3} \mathrm{U}\right)$ was added and the enzymatic reaction mixture was incubated for an overall time of 120 min. Every $15 \mathrm{~min}$, an aliquot $(20 \mu \mathrm{L})$ was sampled and pourred with an alkaline buffer $(30 \mu \mathrm{L}, \mathrm{pH}$ 12.3, final concentration $30 \mu \mathrm{M}$ ) containing the enhancers (CTAB, $2 \mathrm{mM}$, 5-(stearoylamino)fluorescein $0.18 \mathrm{mM}$ ). Luminescence measurements were recorded (into an ultra-micro fluorescence cell Hellma ${ }^{\circledR}$, 105.51-QS, $3 \times 3 \mathrm{~mm}, 45 \mu \mathrm{L}$ ) for each aliquot between 490 and $570 \mathrm{~nm}$ during $10 \mathrm{~min}$.

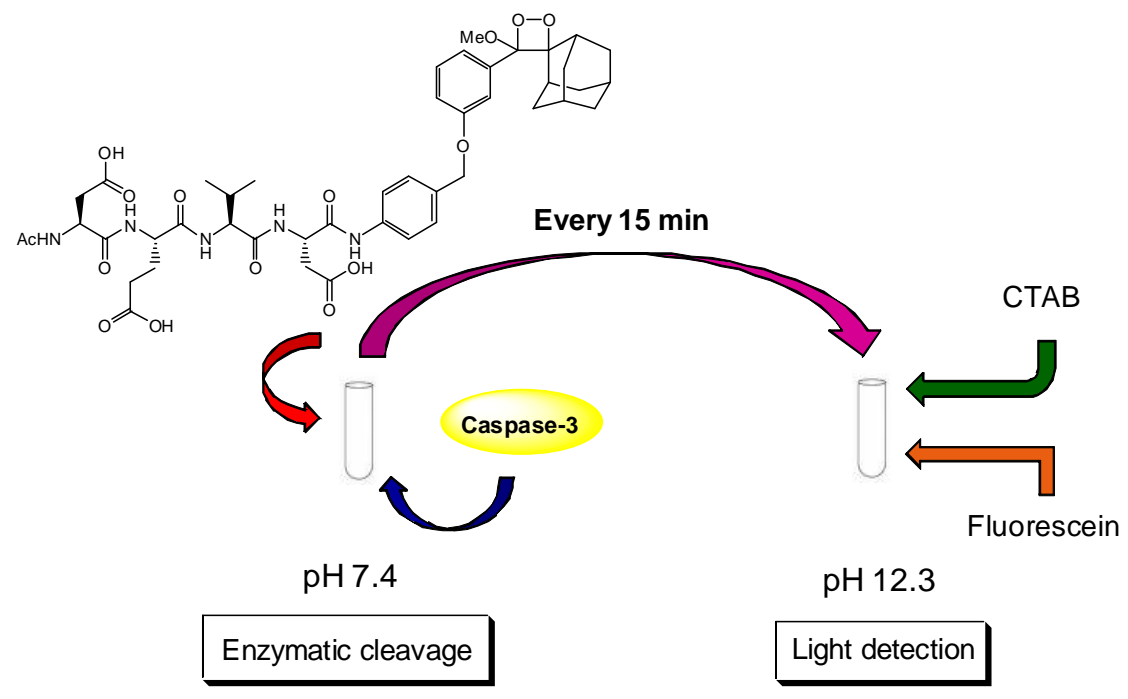

Figure S2. Experimental procedure for the in vitro detection of caspase-3.

A detection of light at $530 \mathrm{~nm}$ corresponding to the emission wavelength of the fluorescein has been observed, highlighting the efficient energy transfer between the dioxetane (whose normal emission wavelength is $460 \mathrm{~nm}$ ) and the fluorphore (Figure S3).

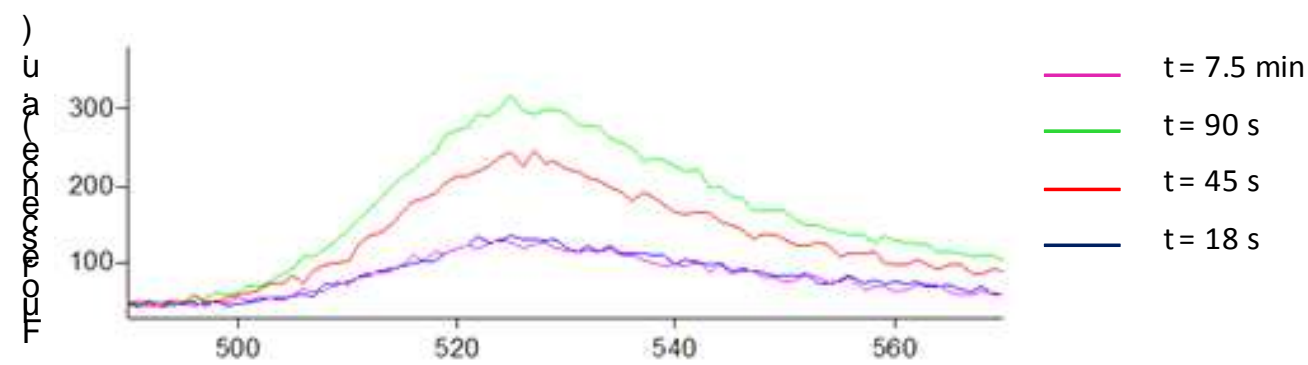

Figure S3. Light emission recorded at $530 \mathrm{~nm}$ during $10 \mathrm{~min}$ (incubation time $105 \mathrm{~min}$ ) 
The total luminescence has been represented as a function of the incubation time, showing an increase of the light emission during the course of the enzymatic cleavage (Figure S4).

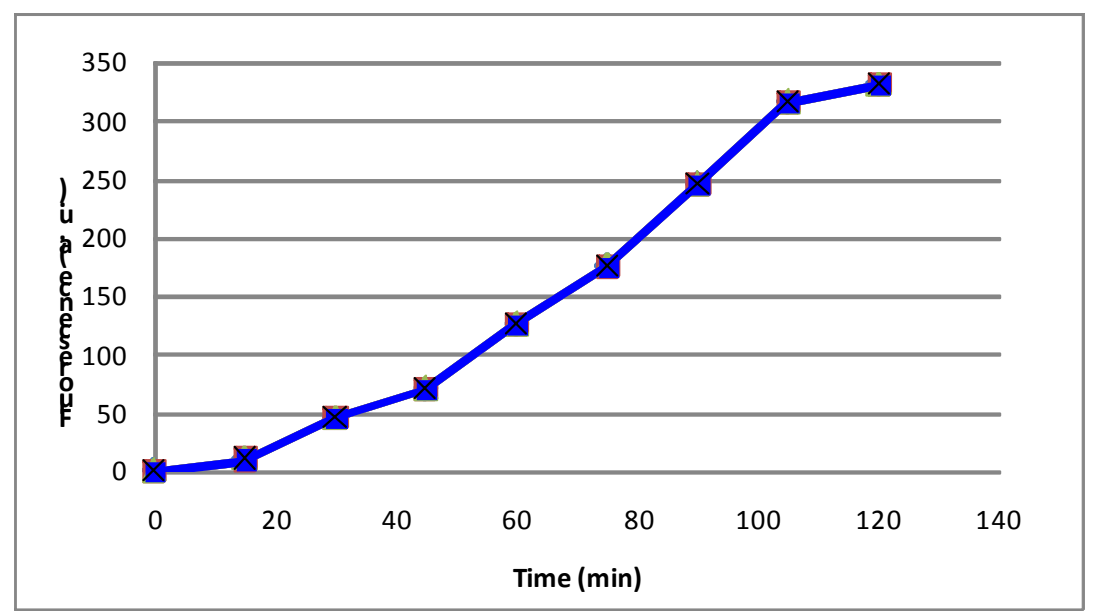

Figure S4. Total light emission recorded between 490 and $570 \mathrm{~nm}$ after 15, 30, 45, 60, 75, 90, 105 and 120 min of incubation

A control experiment was performed without adding caspase-3 enzyme and as expected, no light could be detected during the $2 \mathrm{~h}$ of this experiment (Figure S5).

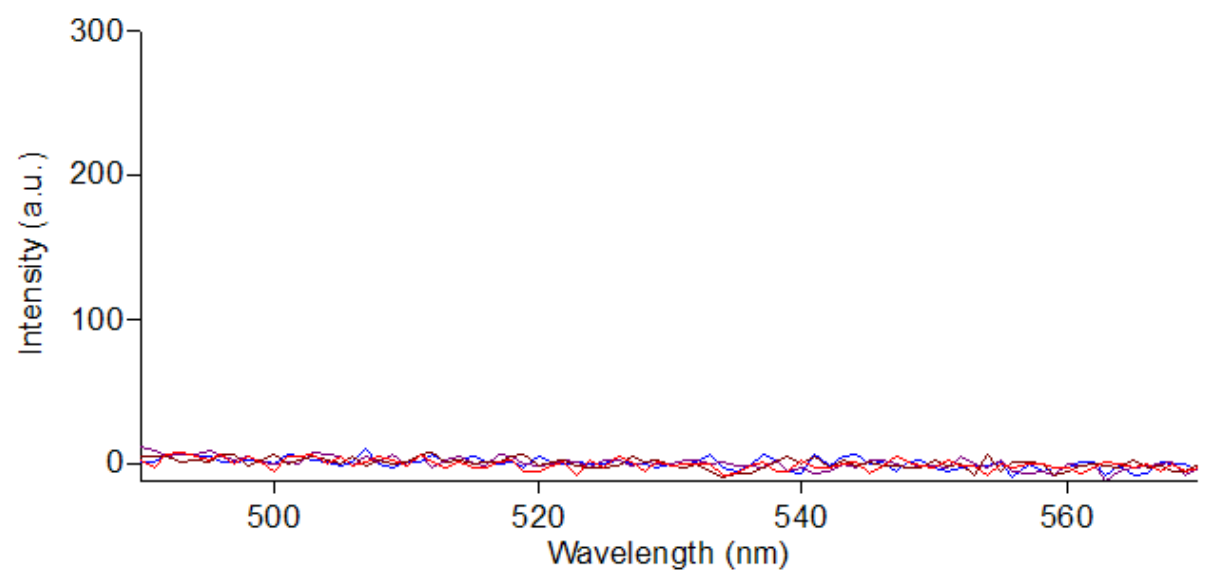

Figure S5. Control experiment without caspase-3 enzyme in the medium after 60 min of incubation (same profiles were obtained after 15, 30, 45, 75, 90, 105 and $120 \mathrm{~min}$ ).

\section{B. Caspase-3 detection limit of the chemiluminescent probe 12:}

In order to determine the detection limit of the chemiluminescent probe 12, a decreasing amount of caspase-3 enzyme was incubated during 60 min with a solution of $12(30 \mu \mathrm{M})$. The total light emission was recorded between 490 and $570 \mathrm{~nm}$ during $10 \mathrm{~min}$ and reported as a function of the enzyme concentration (Figure S6). 


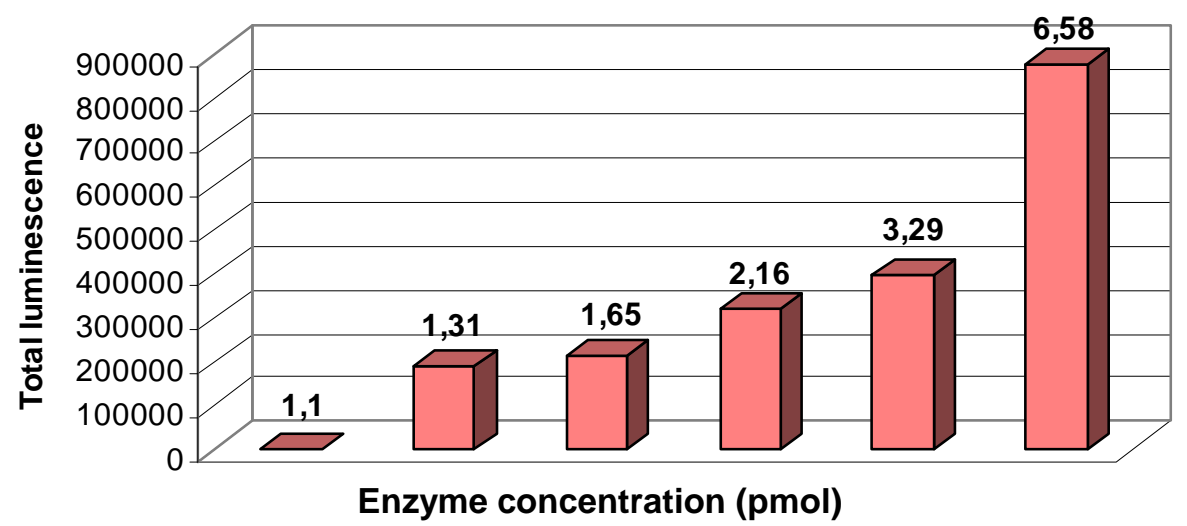

Figure S6. Determination of the detection limit of the chemiluminescence probe 12. Light emission could be observed until a caspase- 3 concentration of 1.31 pmol.

\section{Representative control experiments with other peptidases:}

In order to demonstrate the specificity of the cleavage by caspase- 3 enzyme, the chemiluminescent probe 12 was incubated with human recombinant caspase- $9(1 \mu \mathrm{L}, 2.38 \mathrm{U}$ in a caspase- 9 buffer: $0.1 \mathrm{M}$ MES, 10\% PEG, 0.1\% CHAPS, $10 \mathrm{mM}$ DTT, pH 6.5) and A. faecalis recombinant PGA (1.2 mg, $1.9 \mathrm{U}$ in $50 \mathrm{mM}$ phosphate buffer, $\mathrm{pH} \mathrm{7.5)}$ for $60 \mathrm{~min}$. Then, the enzymatic reaction mixture was mixed with an alkaline buffer ( $\mathrm{pH}$ 12.3, final concentration of $1230 \mu \mathrm{M})$ containing the enhancers (CTAB, $2 \mathrm{mM}$, 5-(stearoylamino)fluorescein $0.18 \mathrm{mM}$ ) and light emission was recorded (into an ultra-micro fluorescence cell Hellma ${ }^{\circledR}$, 105.51-QS, 3 x $3 \mathrm{~mm}, 45 \mu \mathrm{L}$ ) between 490 and $570 \mathrm{~nm}$. No light could be detected for both enzymes (Figure S7).

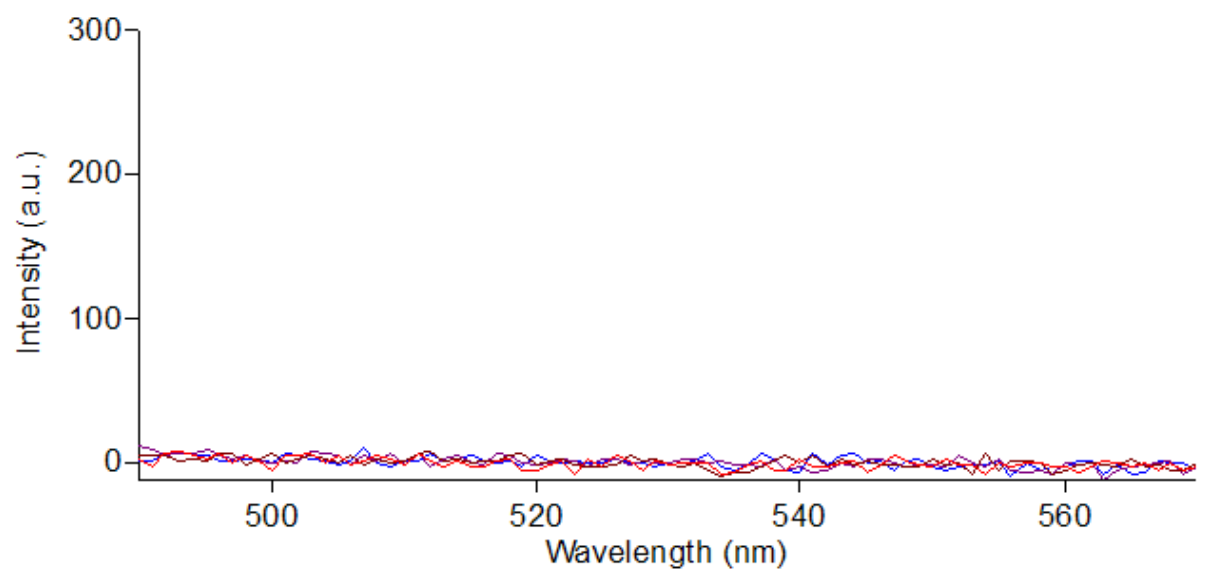

Figure S7. Light emission recorded after $1 \mathrm{~h}$ of incubation with caspase-9 and penicillin amidase.

\section{4. ${ }^{1} \mathrm{H}$ NMR, ${ }^{13} \mathrm{C}$ NMR and ESI mass spectra of compounds 7,9 and $11 .{ }^{1} \mathrm{H}$ NMR and ESI mass spectra of 11'. ESI mass spectrum of dioxetane 12. RP- HPLC elution profiles of compounds 11, 11' and 12.}


${ }^{1} \mathrm{H}$ NMR spectrum of Ac-DEVD-OH $7\left(300 \mathrm{MHz}, \mathrm{CD}_{3} \mathrm{OD}\right)$.

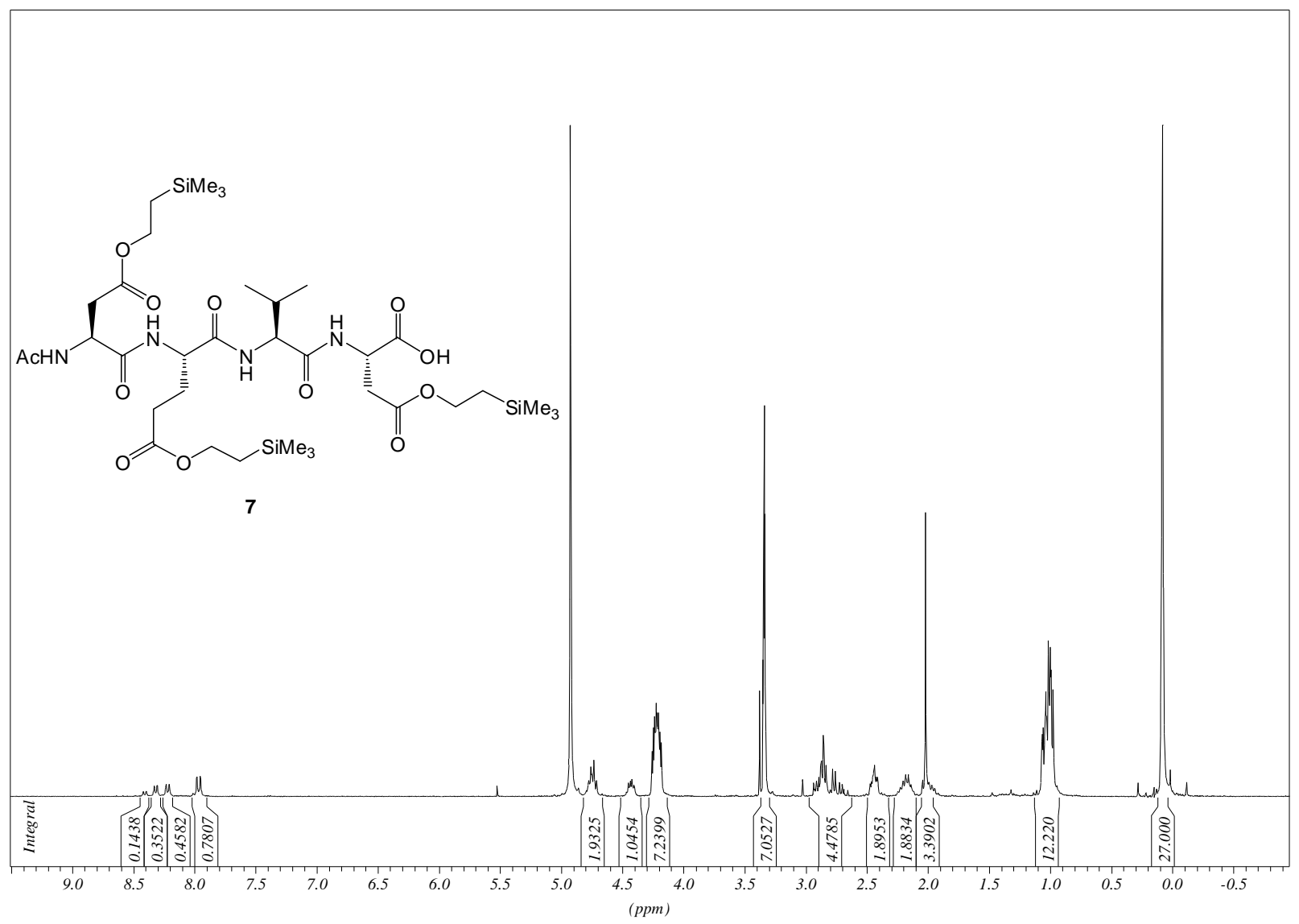

${ }^{13} \mathrm{C}$ NMR spectrum of Ac-DEVD-OH $7\left(75.4 \mathrm{MHz}, \mathrm{CD}_{3} \mathrm{OD}\right)$.

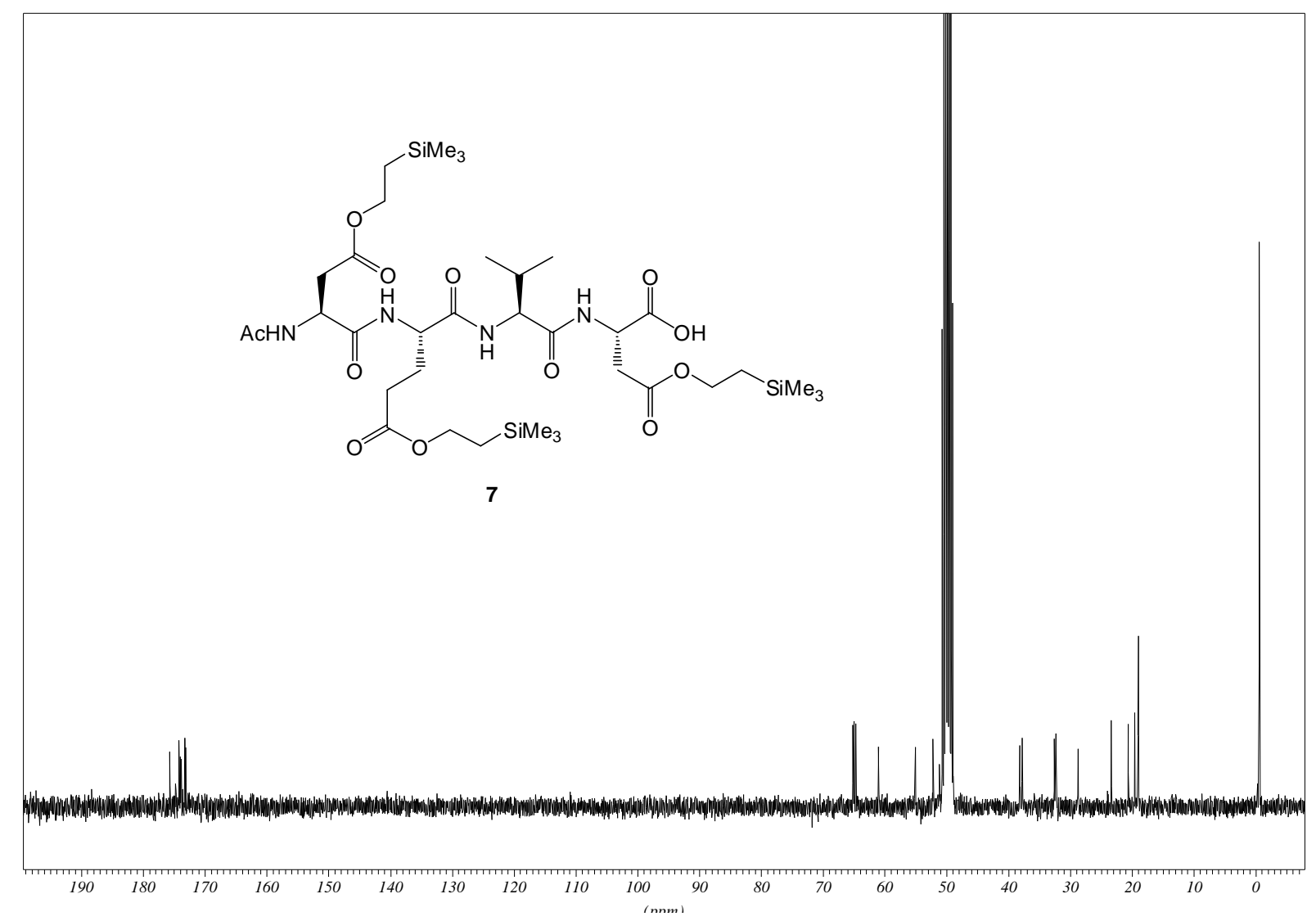


ESI mass spectrum (recorded in the negative mode) of compound 7.

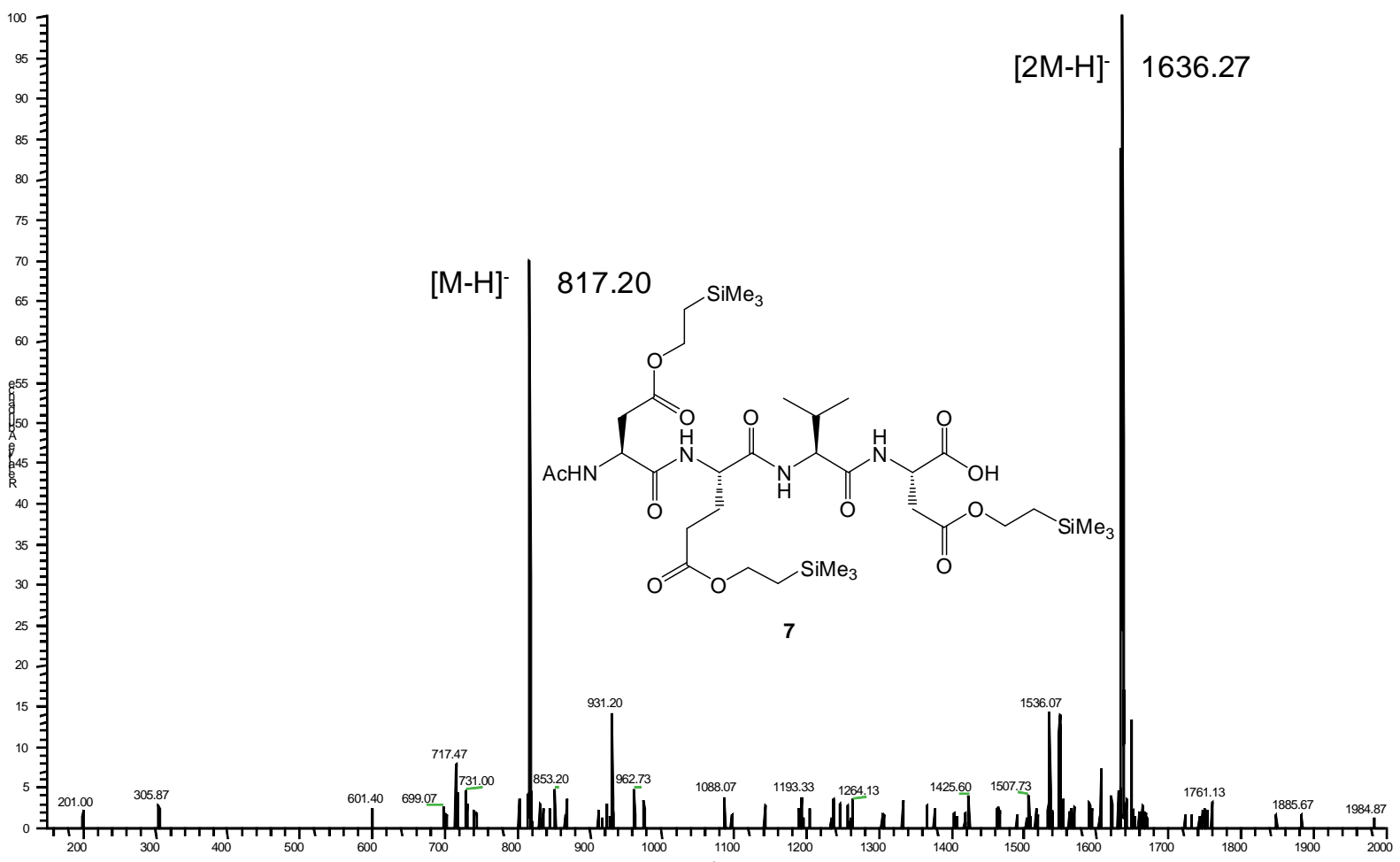

${ }^{1} \mathrm{H}$ NMR spectrum of Ac-DEVD-PABA-OH $9\left(300 \mathrm{MHz}, \mathrm{CD}_{3} \mathrm{OD}\right)$.

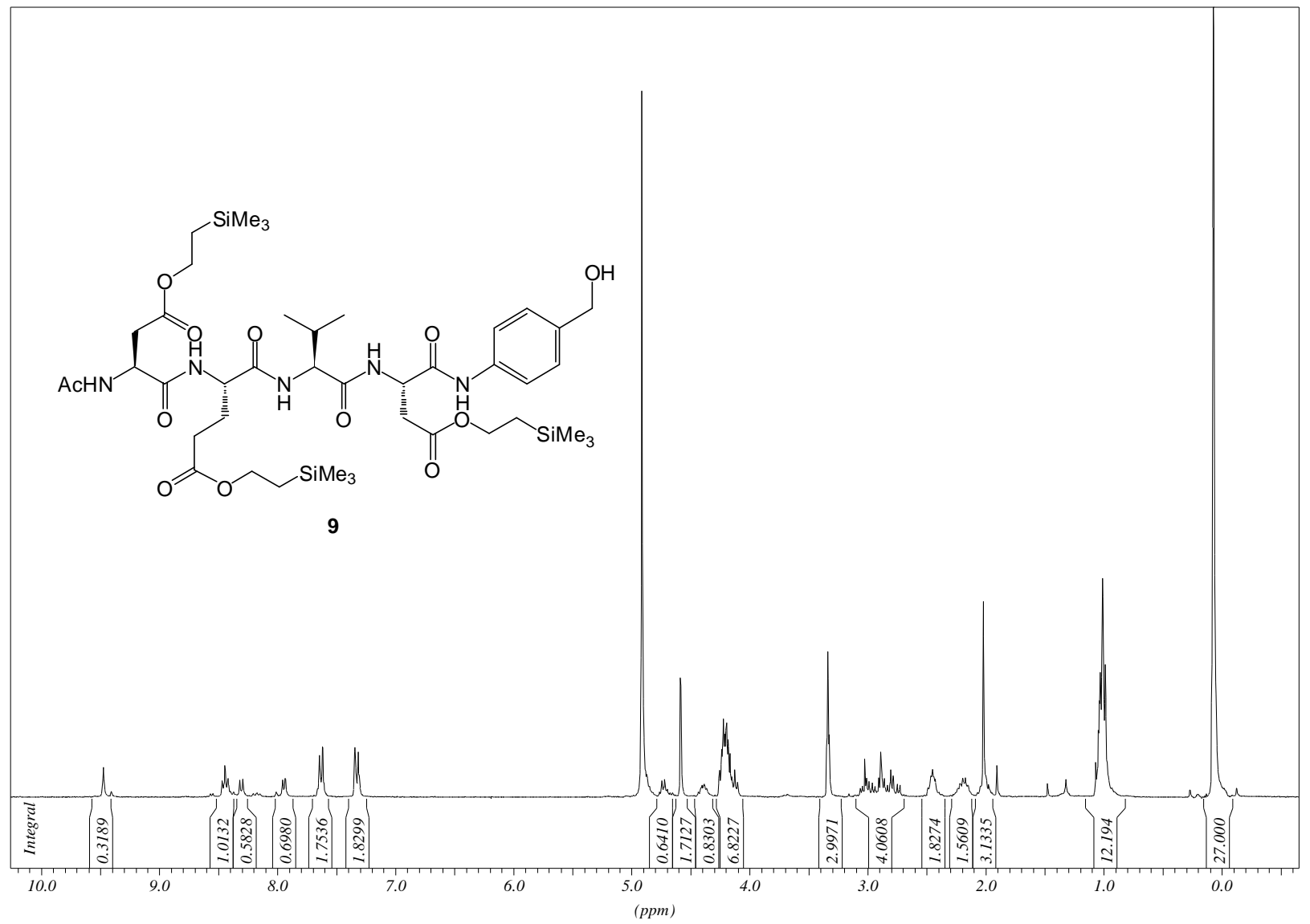


${ }^{13} \mathrm{C}$ NMR spectrum of Ac-DEVD-PABA-OH 9 (75.4 MHz, $\left.\mathrm{CD}_{3} \mathrm{OD}\right)$.

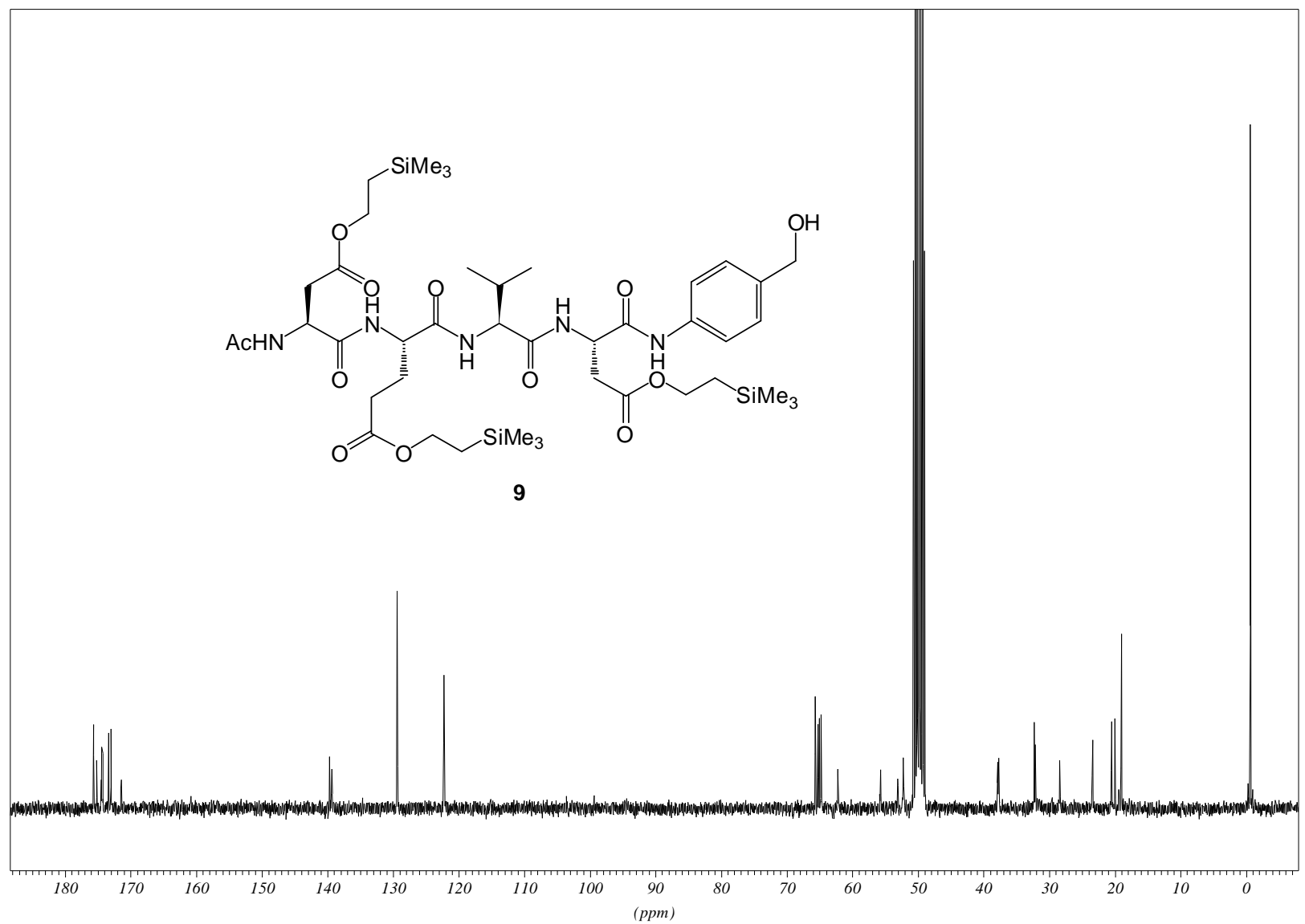

ESI mass spectrum (recorded in the positive mode) of compound 9.

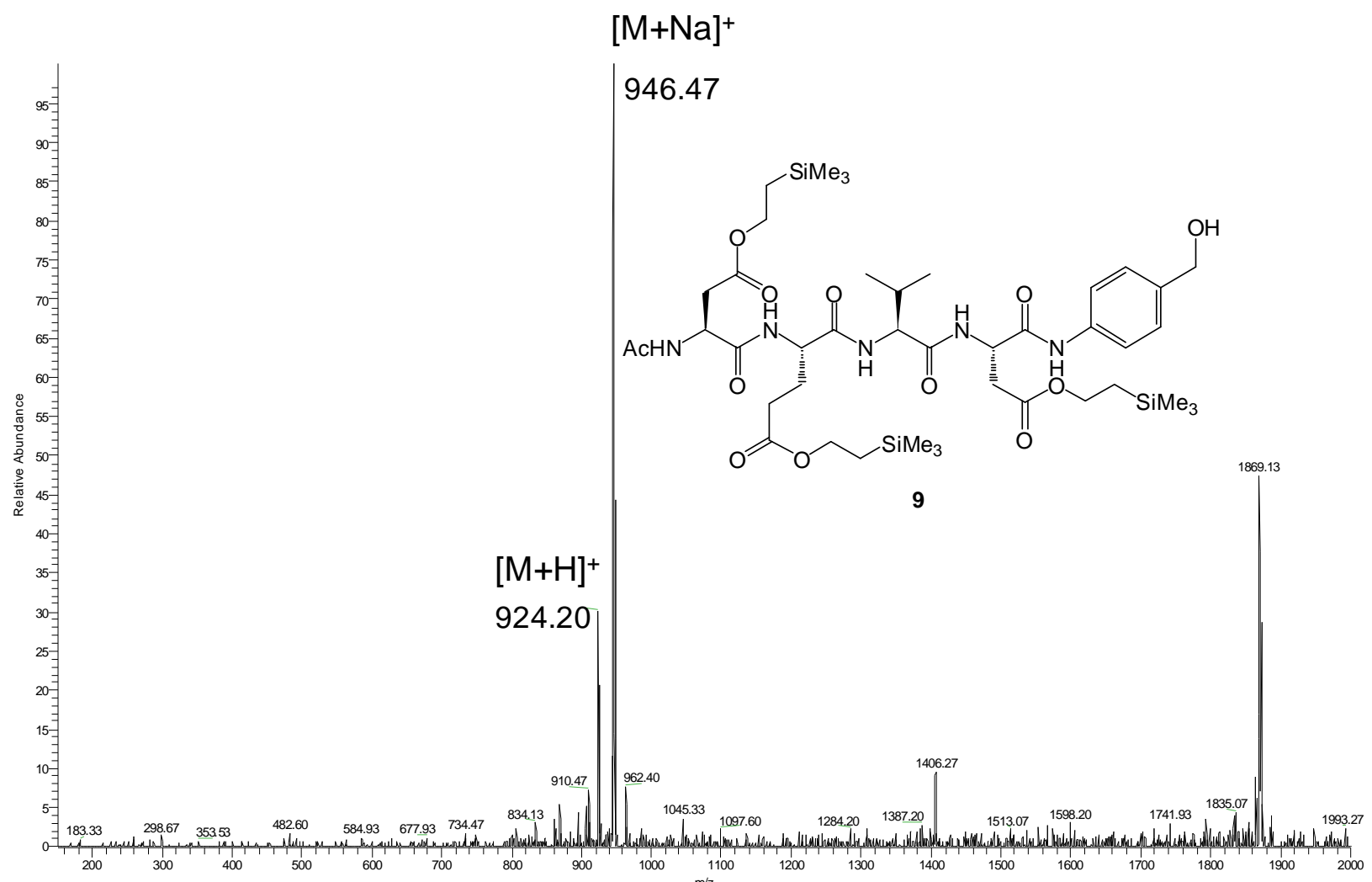


${ }^{1} \mathrm{H}$ NMR spectrum of compound $\mathbf{1 1}\left(300 \mathrm{MHz}, \mathrm{CDCl}_{3}\right)$.

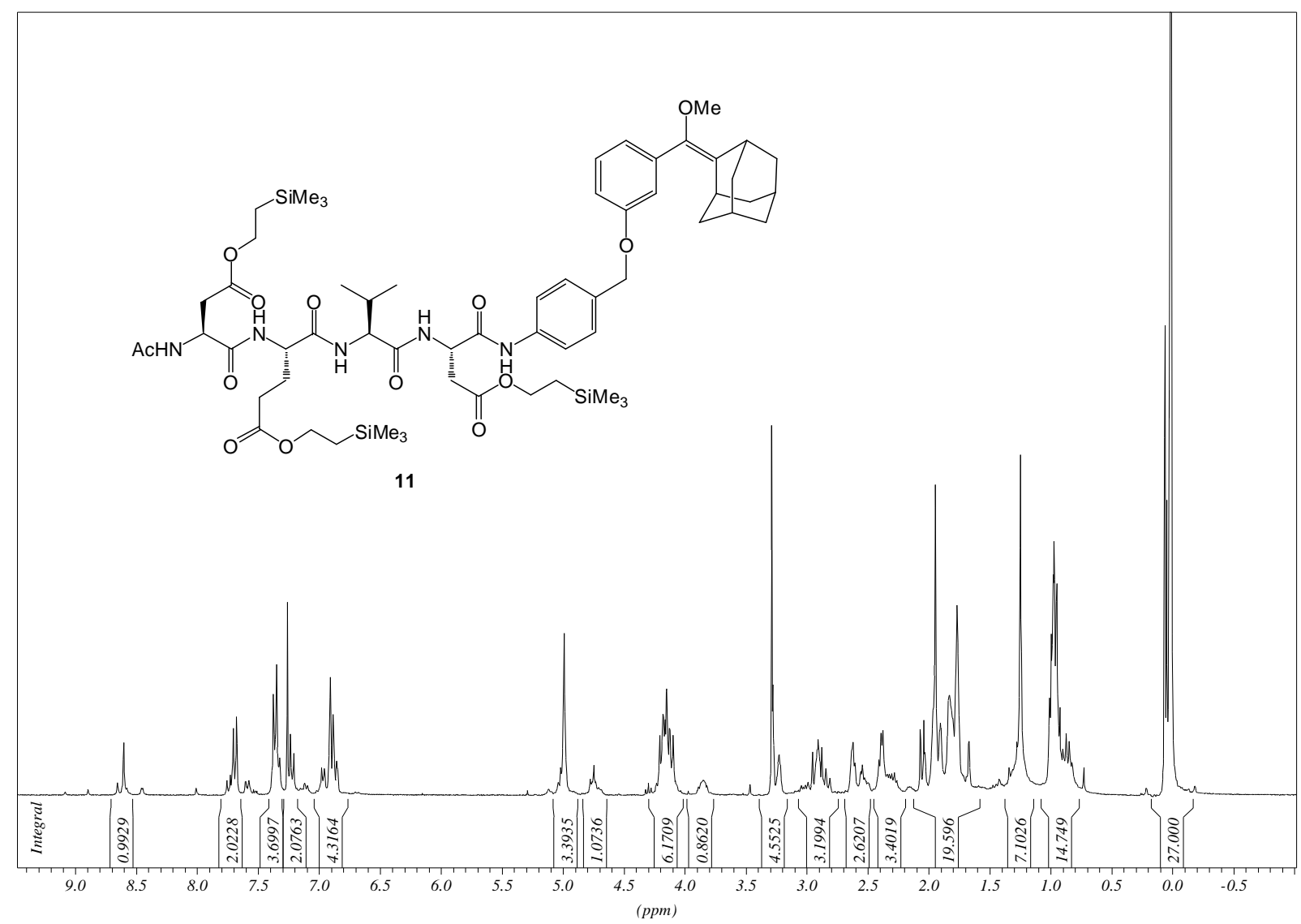

${ }^{13} \mathrm{C}$ NMR spectrum of compound $11\left(75.4 \mathrm{MHz}, \mathrm{CDCl}_{3}\right)$.

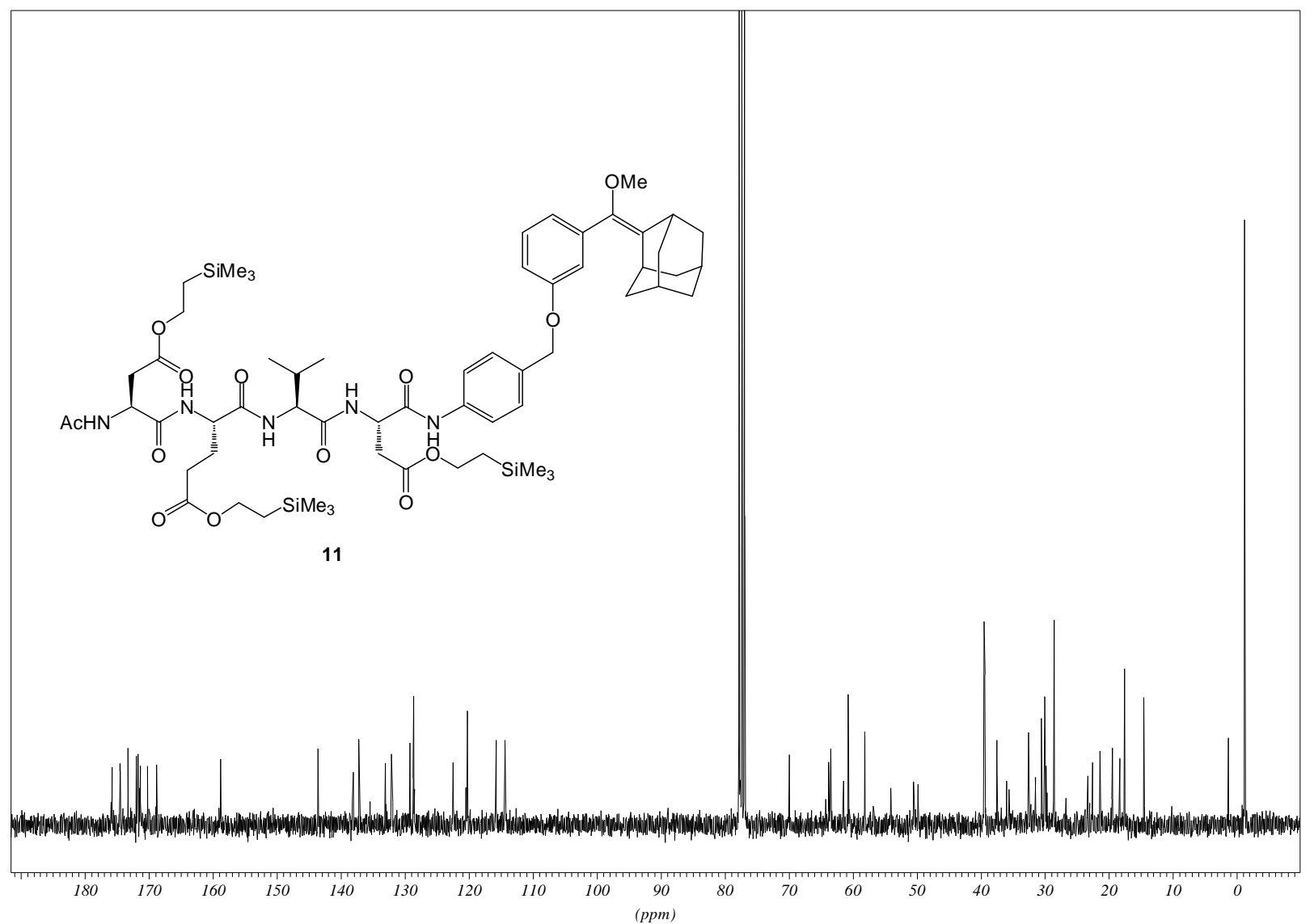


ESI-MS spectrum (recorded in the positive mode) of compound 11.

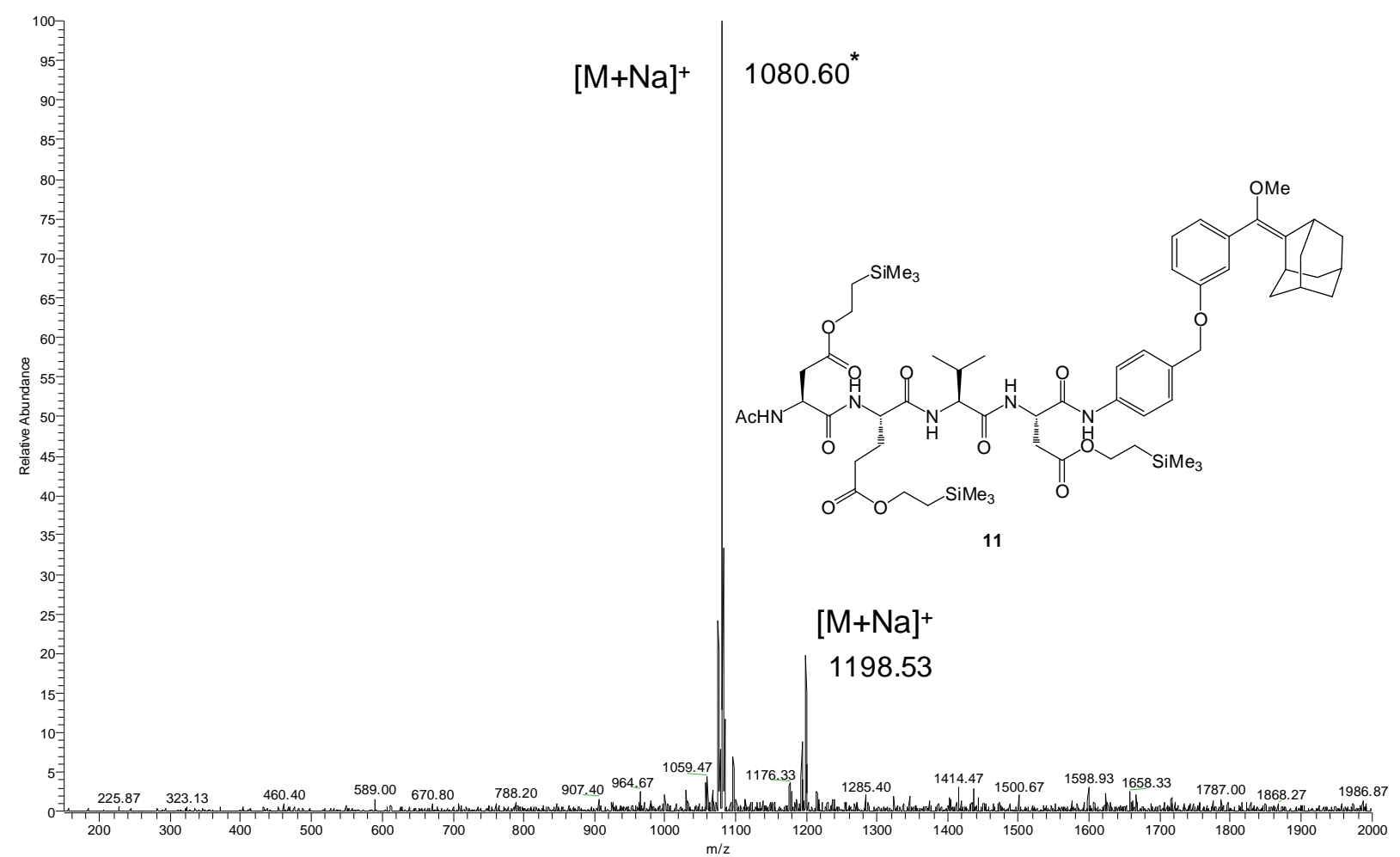

* Only a few amount of the sodium adduct could be detected $\left([\mathrm{M}+\mathrm{Na}]^{+} 1198.53\right)$. The major peak corresponds to the sodium adduct of aspartimide derivative $\left([\mathrm{M}+\mathrm{Na}]^{+} 1080.60\right)$. Such cyclization occured during the ionization process.

${ }^{1} \mathrm{H}$ NMR spectrum of the dioxetane 11' (300 MHz, $\left.\mathrm{CDCl}_{3}\right)$.

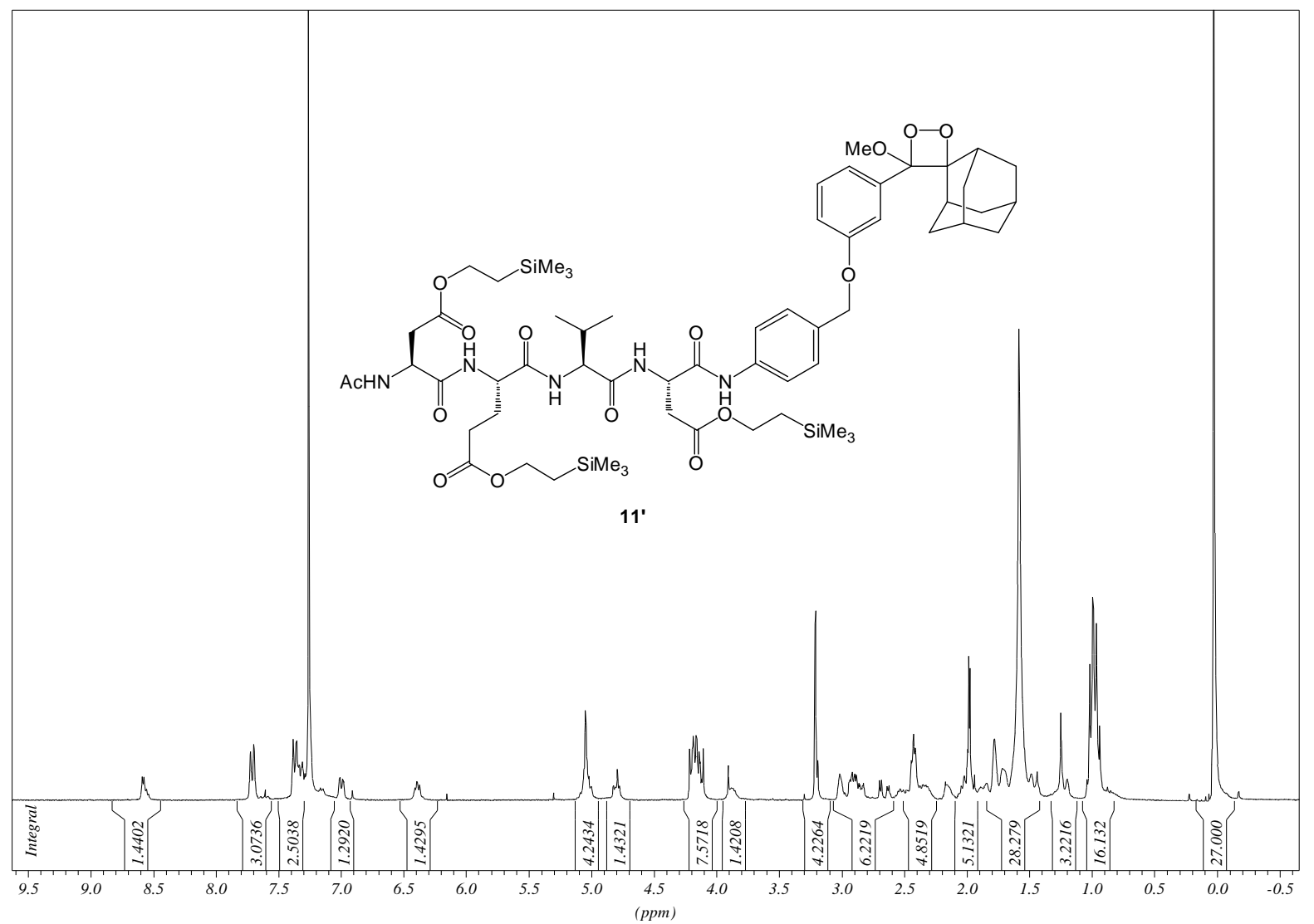


ESI mass spectrum (recorded in the positive mode) of the dioxetane 11'.

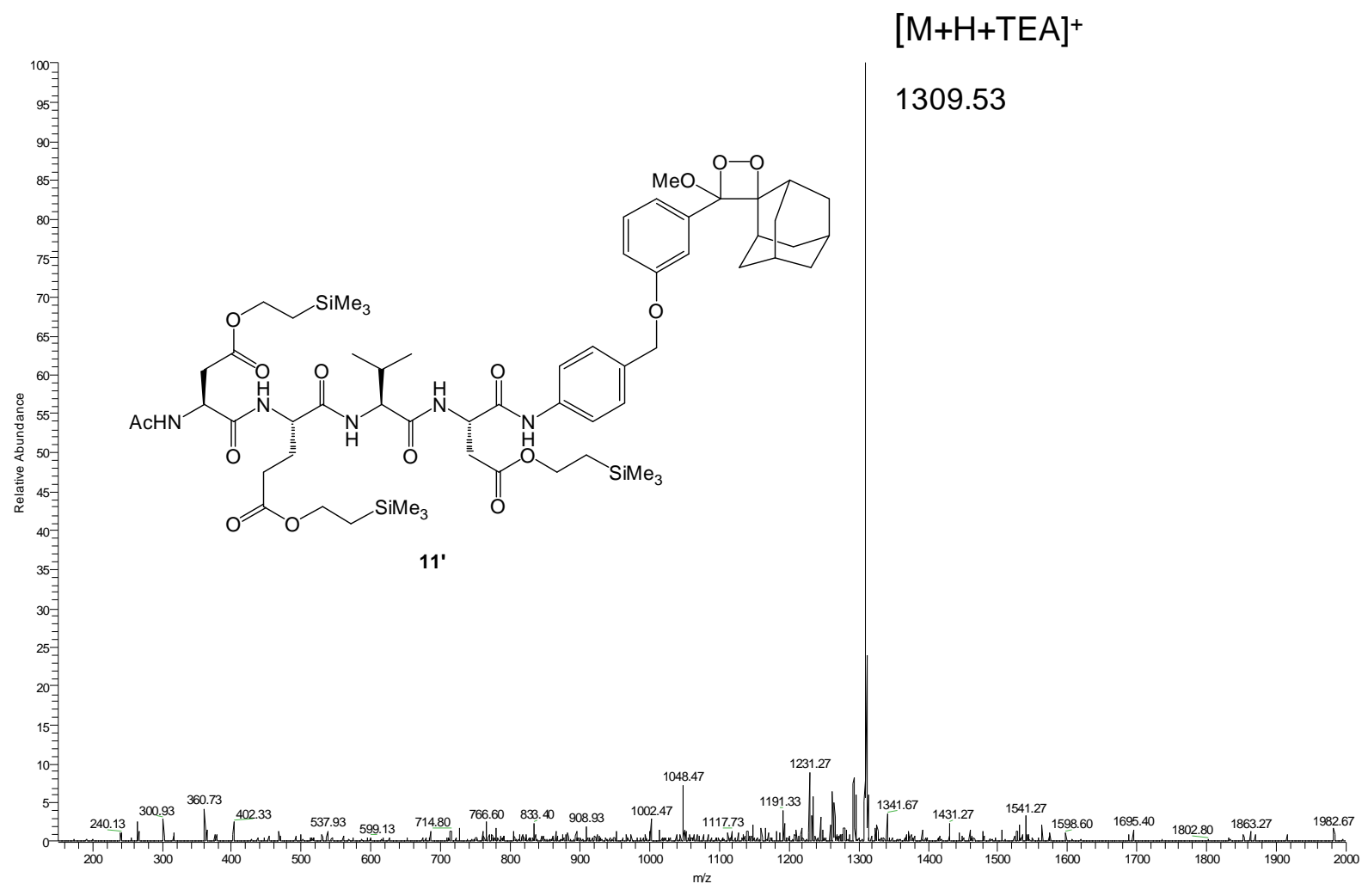

ESI mass spectrum (recorded in the negative mode) of the dioxetane $\mathbf{1 2}$.

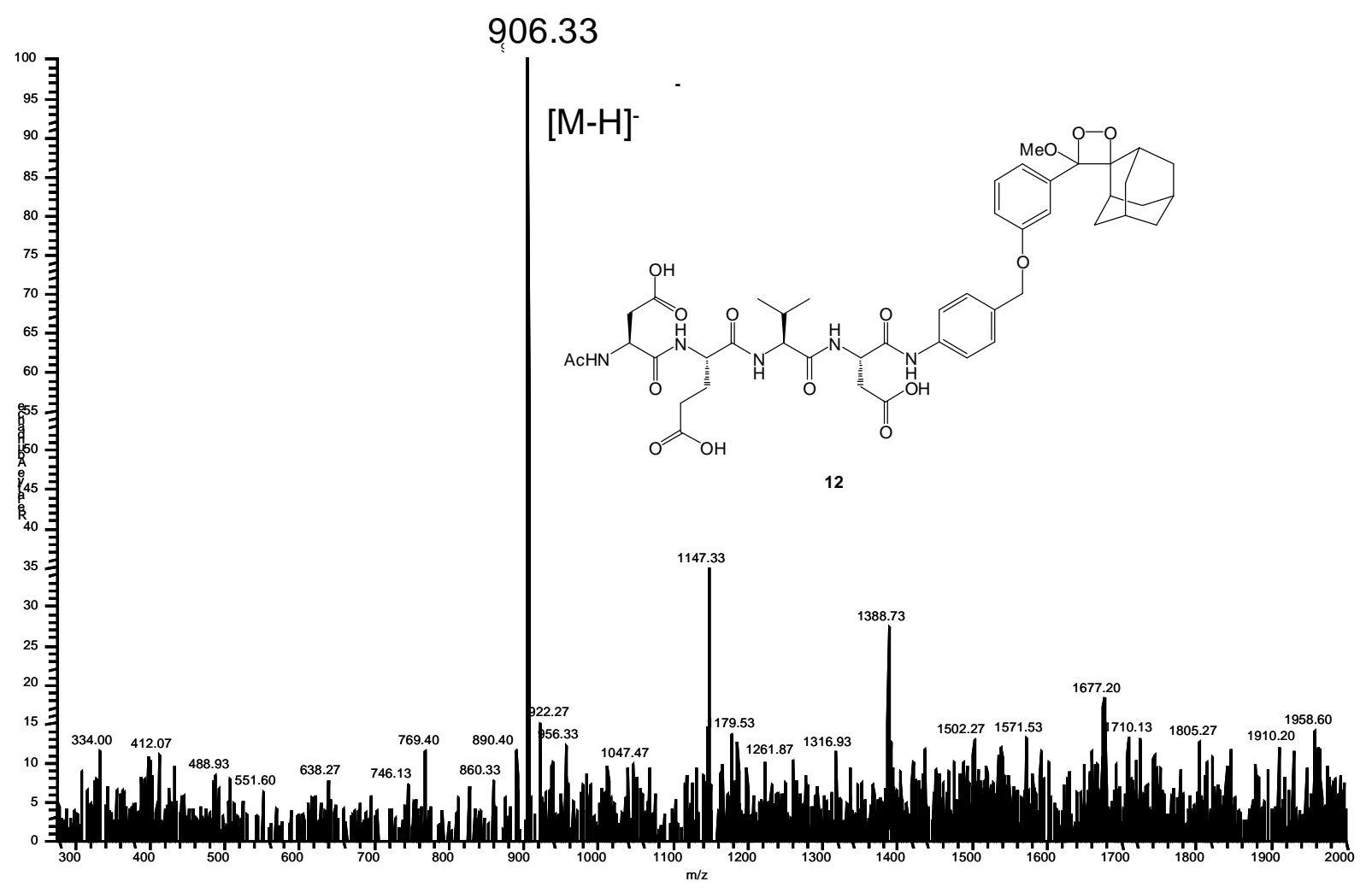


RP-HPLC elution profile of compound 11 (system B).

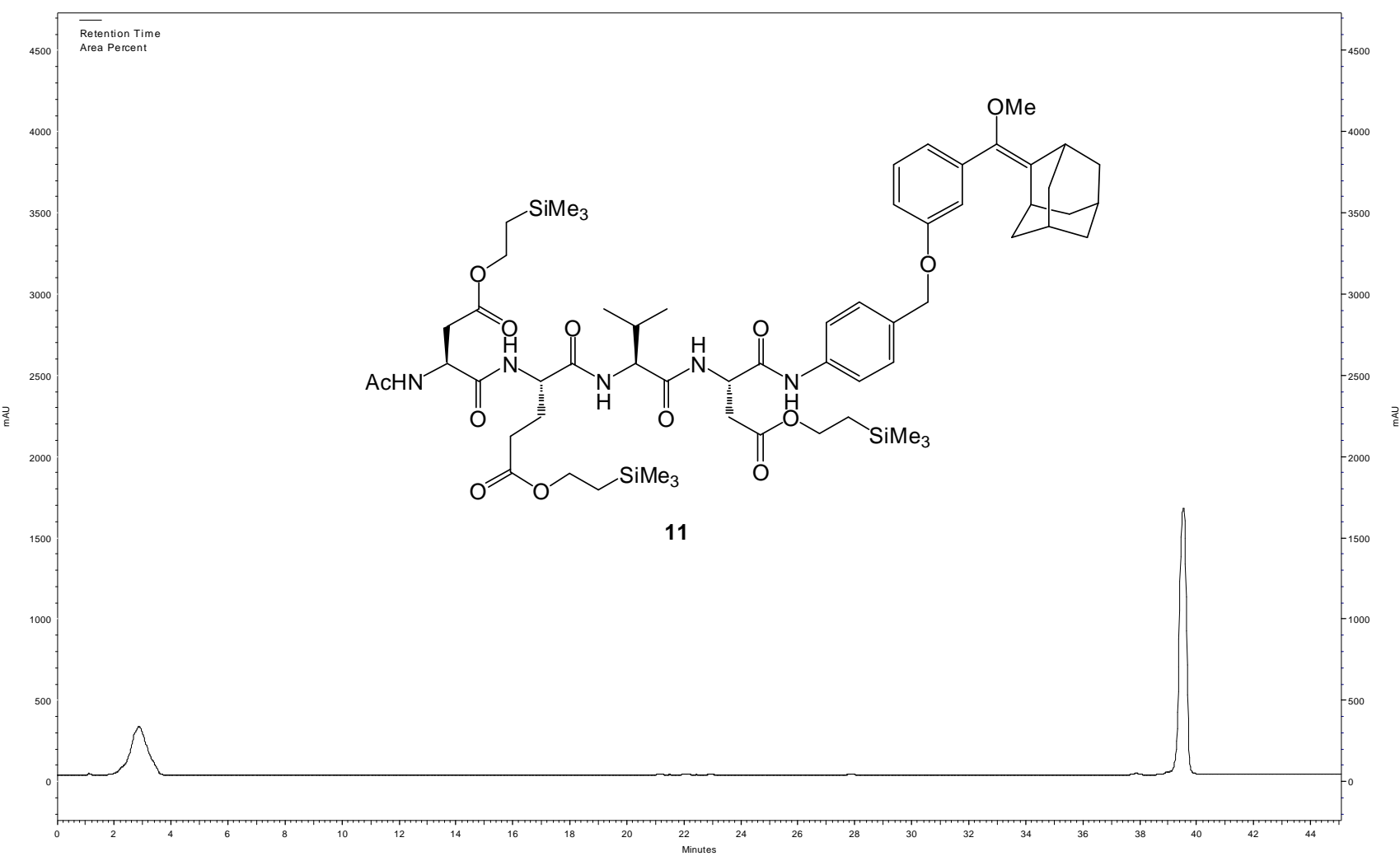

RP-HPLC elution profile of the dioxetane 11' (system B).

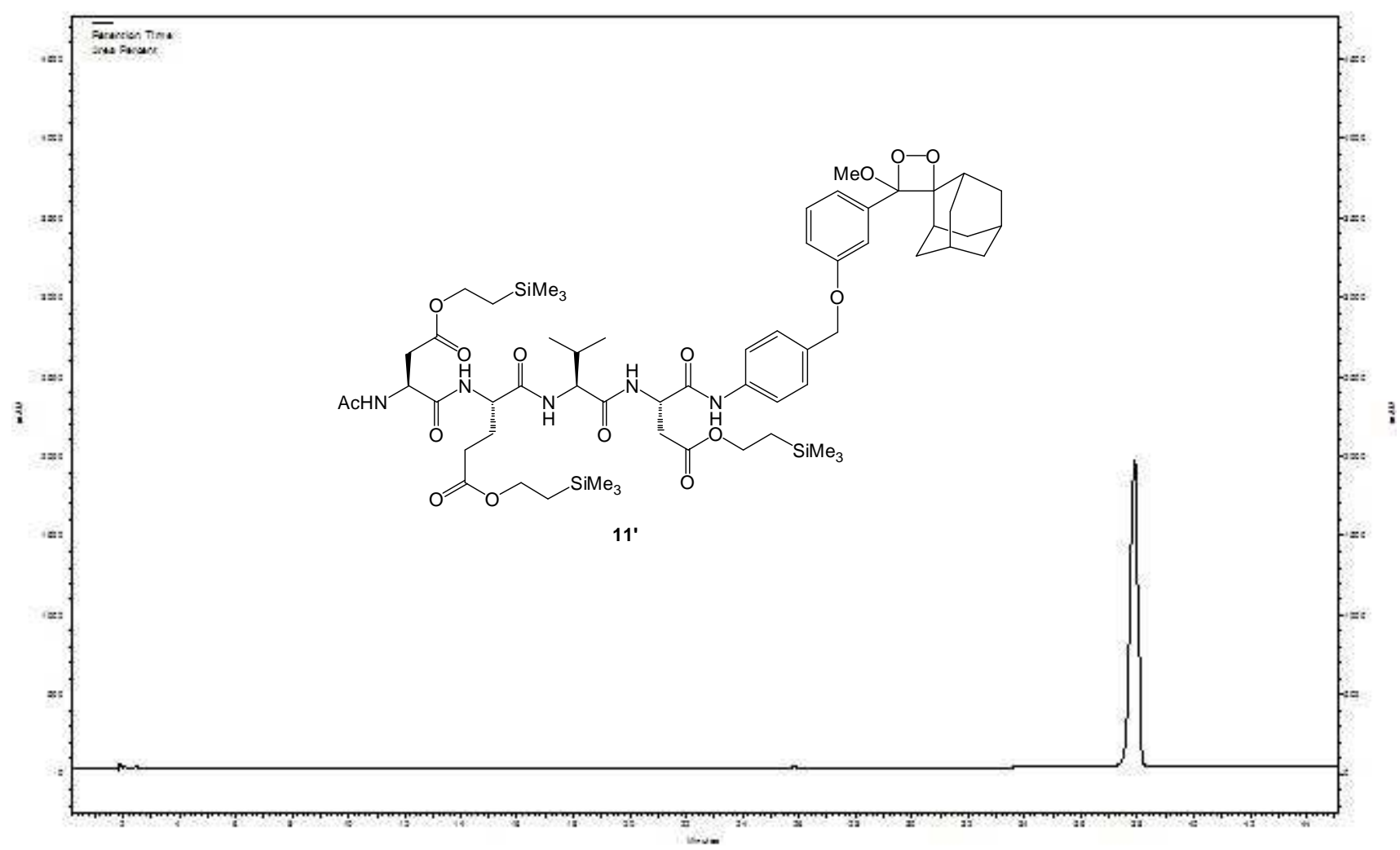


RP-HPLC elution profile of compound 12 (system B).

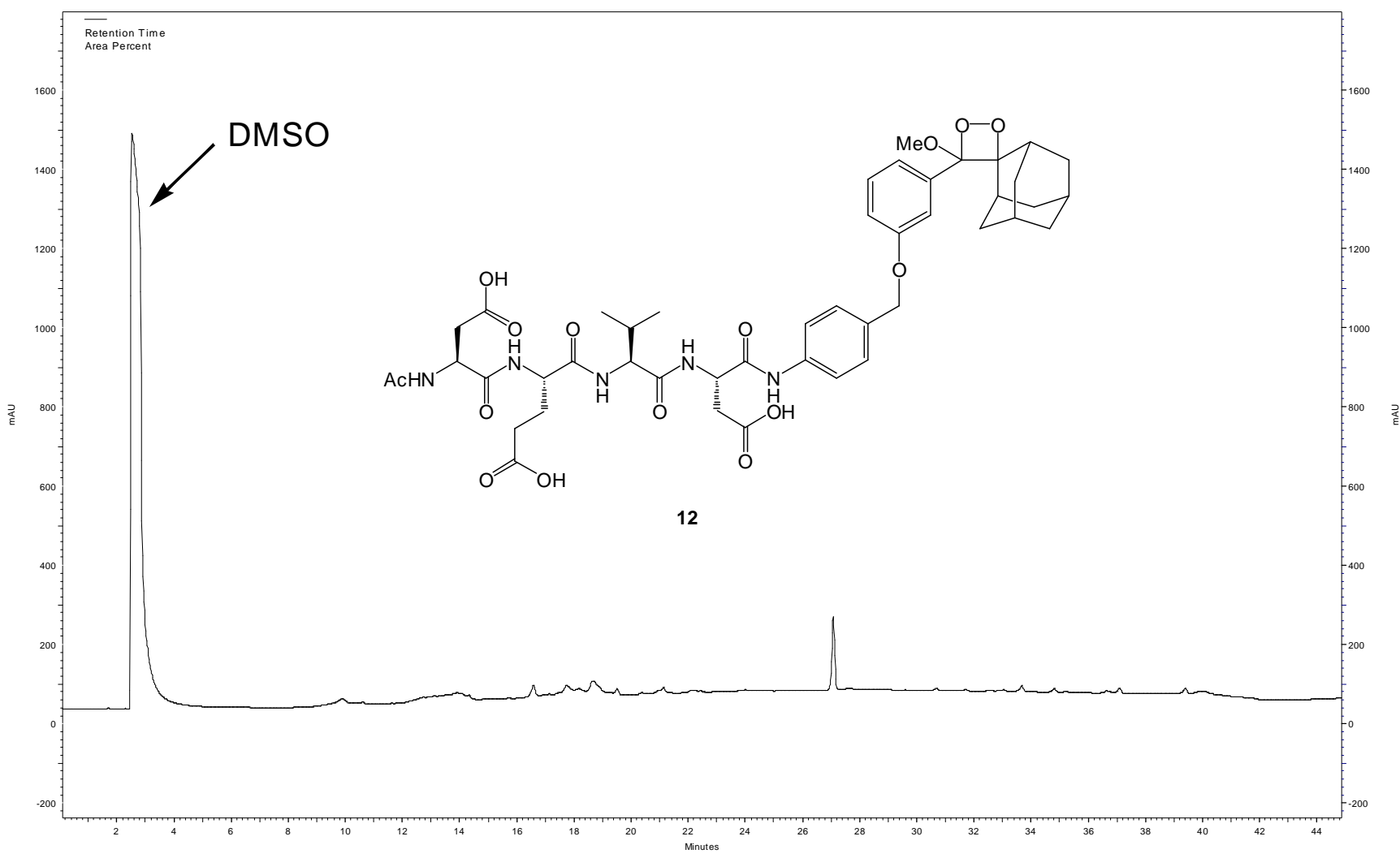

